\title{
Dupilumab en el tratamiento del asma
}

\section{Dupilumab in the treatment of asthma}

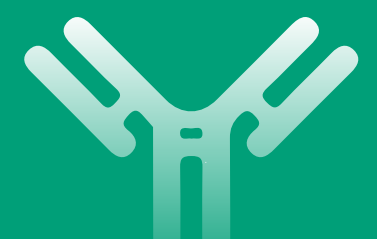

\section{Said Eduardo Arablin-Oropeza, ${ }^{1}$ Víctor González-Uribe, ${ }^{2}$ Blanca E. Del Río-Navarro, ${ }^{3}$ Ana del Carmen García-González, ${ }^{2}$ Elsy M. Navarrete-Rodríguez, ${ }^{3}$ Alberto Valencia ${ }^{2}$}

${ }^{1}$ Medical Scientific Liaison-Immunología, Sanofi Genzyme, Aguascalientes, México

${ }^{2}$ Medical Scientific Liaison-Inmunología, Sanofi Genzyme, Ciudad de México, México

${ }^{3}$ Hospital Infantil de México Federico Gómez, Servicio de Alergia e Inmunología Clínica, Ciudad de México, México

\section{ORCID}

Said Eduardo Arablin-Oropeza, 0000-0001-7588-5374; Víctor González-Uribe, 0000-0001-9053-7108; Blanca E. Del Río-Navarro, 0000-0001-6441-8869; Ana del Carmen García-González, 0000-0002-89696686; Elsy M. Navarrete-Rodríguez, 0000-0001-9876-3206; Alberto Valencia, 0000-0002-2733-9421

Correspondencia: Víctor González-Uribe. victor.gonzalez@sanofi.com

Recibido: 2020-07-02

Aceptado: 2020-09-20

DOl: 10.29262/ram.v67i7.779

Este artículo debe citarse como: Arablin-Oropeza SE, González-Uribe V, Del Río-Navarro BE, García-González AC, Navarrete-Rodríguez EM, Valencia A. Dupilumab en el tratamiento del asma. Rev Alerg Mex. 2020;67 Supl 3:s37-s58.

\section{Abstract}

Dupilumab is a fully human monoclonal antibody against the interleukin [IL]-4 and IL-4/IL-13 receptor complexes. These are key cytokines in driving type 2 inflammation, a dominant and largely inflammatory pathway in asthma. Trials evaluating the efficacy of dupilumab in asthma include three pivotal, placebo-controlled, phase $2 \mathrm{~b}$ or 3 trials of 24-52 weeks treatment duration in patients aged below 12 years with moderate-to severe asthma [inadequately controlled with medium-to-high dose inhaled corticosteroids] or severe asthma [dependent on oral corticosteroids for control]. In these studies, adding subcutaneous dupilumab to background therapy was generally well tolerated and reduced the rate of severe asthma exacerbations, improved lung function, as well as asthma control and, health-related quality of life, and enabled oral corticosteroids maintenance doses to be reduced without impacting asthma control. Dupilumab displayed efficacy across various patient subgroups, although those with heightened type 2 immune activity, tended to have a more prominent treatment benefit. Dupilumab is consequently widely indicated [and a valuable treatment option] as an add-on therapy in patients aged below 12 years who have severe/moderate-to-severe asthma with a type 2 inflammation/eosinophilic phenotype despite conventional treatments or have oral corticosteroids-dependent asthma.

Key words: Asthma; Dupilumab; Monoclonal; Forced expiratory volume in first second; Exacerbation 


\section{Resumen}

Dupilumab es un anticuerpo monoclonal humano contra receptores de interleucina [IL]-4 e IL-4/IL-13. Estas son citocinas clave en la génesis de la inflamación tipo 2, predominante en los pacientes con asma. Los ensayos clínicos que evalúan la eficacia de dupilumab incluyen tres ensayos pivotales controlados versus placebo fase 2 b o 3 de 24 a 52 semanas en pacientes $\geq 12$ años, con asma moderada a grave (no controlada con dosis media a alta de corticosteroides inhalados] o asma grave [dependiente de corticosteroides orales]. En estos estudios, la suma de dupilumab al tratamiento se toleró adecuadamente y redujo la tasa de exacerbaciones graves, mejoró la función pulmonar, así como el control del asma y la calidad de vida, de igual forma redujo las dosis de corticosteroides sistémicos orales sin afectar el control. Dupilumab mostró eficacia en varios subgrupos de pacientes, aunque aquellos con inflamación tipo 2 mostraron un beneficio más destacado. Dupilumab está indicado [y es una opción terapéutica valiosa] en pacientes $\geq 12$ años de edad que tienen asma de moderada o grave con inflamación tipo 2/fenotipo eosinofílico, descontrolada a pesar de los tratamientos convencionales o en aquellos con dependencia a corticosteroides sistémicos orales para el control.

Palabras clave: Asma; Dupilumab; Monoclonal; Volumen espiratorio forzado en el primer segundo; Exacerbación

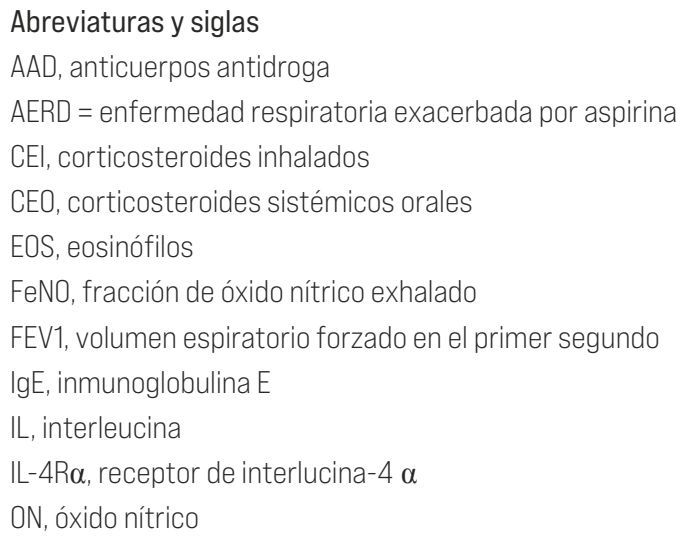

\section{Introducción}

El asma es una enfermedad pulmonar heterogénea crónica, caracterizada por obstrucción reversible al flujo del aire, hiperreactividad de la vía aérea e inflamación de las vías respiratorias de predominio bronquial; ${ }^{1}$ de estas propiedades, la inflamación constituye una pieza clave, ya que determina en gran parte la gravedad y frecuencia de los síntomas, entre algunas otras características de la enfermedad.

Las vías o mecanismos inflamatorios en el asma pueden variar entre pacientes, aunque el perfil que domina o prevalece en muchos es la inflamación tipo $2 .^{2}$ Esta inflamación abarca fenotipos eosinofílicos, alérgicos y algunos otros, que comparten un perfil de células y citocinas común dentro de las que se incluyen interleucina (IL)-4, IL-5 e IL-13 2,3 (figura 1).

Estas citocinas ejercen diversos efectos claves para la enfermedad, por ejemplo, IL-4/IL-13 fomentan el desarrollo de células caliciformes de las vías respiratorias, aumentan la secreción mucosa, la síntesis de óxido nítrico $(\mathrm{ON})$ y promueven una mayor contractibilidad del músculo liso, así como una mayor producción de inmunoglobulina $\mathrm{E}$ (IgE), favoreciendo, además, procesos de remodelación bronquial mediante la diferen- 


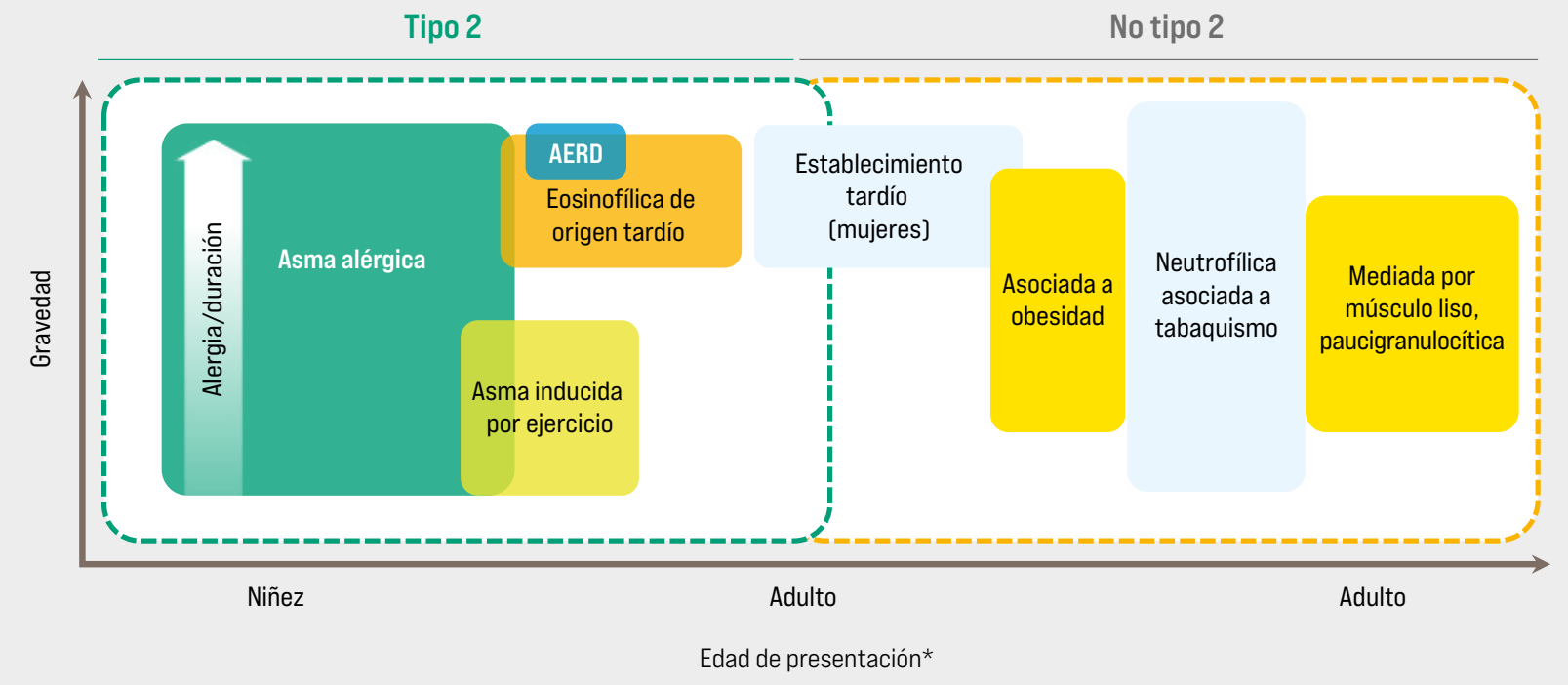

Figura 1. Fenotipos distintos de asma que se sobreponen. Aunque esta tendencia se observa en la mayoría de los pacientes con asma, puede que no sea aplicable para todos los casos. El tamaño de las figuras sugiere relativamente la proporción de la población. AERD = enfermedad respiratoria exacerbada por aspirina. Adaptación de Wenzel SE. Asthma phenotypes: the evolution from clinical to molecular approaches. Nat Med. 2012;18[5]:716-725.

ciación de fibroblastos a miofibroblastos ${ }^{3,4}$ (figura 2); aunado a todo esto, amplifican la respuesta de otras citocinas fundamentales en la diferenciación, maduración y supervivencia de los eosinófilos como IL-5.

Las inflamación tipo 2 contribuye considerablemente al asma grave y ocasiona que aproximadamente la mitad de estos pacientes no alcance un control adecuado con tratamientos convencionales, lo que representa un desafío en relación a su evaluación diagnóstica y un alto consumo de los recursos de atención médica. ${ }^{5} \mathrm{El}$ esfuerzo en la búsqueda de tratamientos dirigidos al espectro de estas citocinas inflamatorias clave como IL-4, IL-5 e IL-13 ha derivado en los últimos años en el desarrollo de terapias que evidencian la importancia de esta señalización ${ }^{6}$ y, en este sentido, la utilización de biomarcadores de inflamación tipo 2 (por ejemplo, eosinófilos [EOS] en esputo/EOS séricos, IgE sérica total, fracción exhalada de óxido nítrico [FeNO] y ciertas proteínas epiteliales bronquiales [por ejemplo, periostina]) permite identificar a los pacientes propensos a responder a tales tratamientos. ${ }^{2,3}$

Una de las terapias biotecnológicas más recientes y la primera en brindar un bloqueo dual de la señalización de las citocinas clave de inflamación tipo 2 (concretamente IL-4 e IL-13) en el asma, es dupilumab, un anticuerpo monoclonal completamente humano contra la subunidad del receptor de interleucina- $4 \alpha(\mathrm{IL}-4 \mathrm{R} \alpha)$. Dupilumab está aprobado actualmente en México y Estados Unidos para dermatitis atópica de moderada a grave y rinosinusitis crónica con poliposis nasal; en varios países (Estados Unidos, ${ }^{7}$ la Unión Europea $^{8}$ y proximamente en México) también está aprobado para el tratamiento de mantenimiento complementario para casos de asma grave, asma de difícil control de moderada a grave con inflamación tipo 2 o asma con fenotipo eosinofílico (tomando como referencia las diversas indicaciones aprobadas en esos países). Este artículo revisa datos relevantes para el uso subcutáneo de dupilumab específicamente en asma, con enfoque en los regímenes recomendados. 


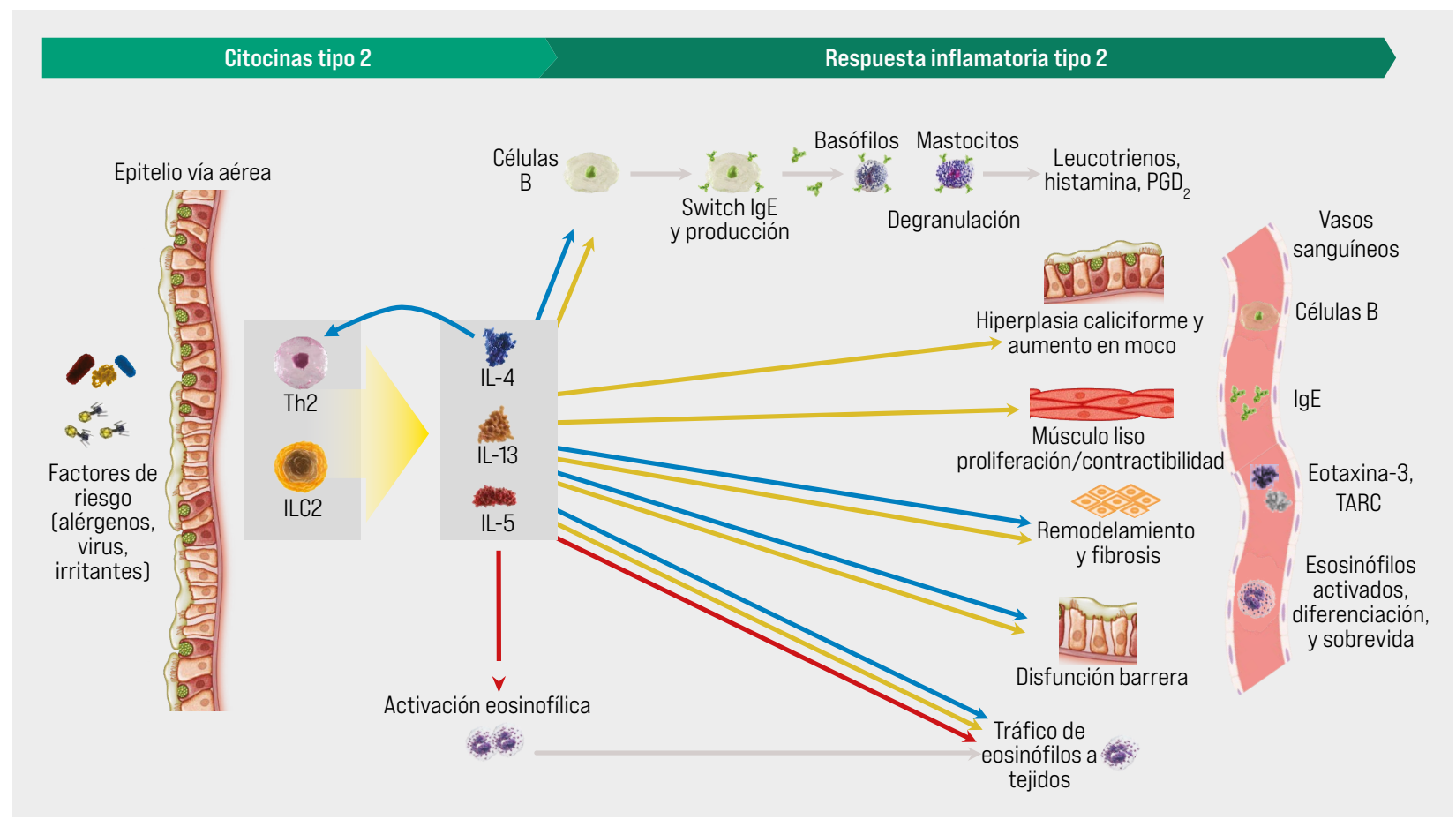

Figura 2. La inflamación tipo 2 conjunta mecanismos adaptativos [Th2] e innatos [ILC2]; estas células producen las citocinas clave tipo 2: IL-4, IL-13 e IL-5. Estas citocinas clave tiene acción biológica en diversas células del sistema respiratorio, condicionando un amplio margen de acciones biológicas que dan como consecuencia los signos y síntomas de la enfermedad. La inflamación tipo 2 está caracterizada por eosinófilos y FeNO alta y puede estar acompañada de atopia. FeNO = fracción exhalada de óxido nítrico, IL = interleucina, $\mathrm{PGD}_{2}=$ prostaglandina D2, Th2 = células T cooperadoras tipo 2 , ILC2 = células linfoides innatas tipo 2, TARC = quimiocina regulada y activada del timo.

\section{Propiedades farmacodinámicas y farmacocinéticas de dupilumab}

Dupilumab se une específicamente y con alta afinidad a la subunidad IL-4R $\alpha$ compartida por el complejo receptor de IL-4 tipo I (IL-4 $\alpha / \gamma \mathrm{c}$ ) y el complejo receptor de IL-4/IL-13 tipo II (IL-4 $\alpha /$ IL-13R $\alpha$ ); al hacerlo, inhibe la señalización de IL-4 e IL-13 (figura 3). ${ }^{7,8}$ Dado el papel clave que desempeñan IL-4 e IL-13 en el establecimiento de la inflamación tipo 2, la inhibición de las vías por parte de dupilumab pueden suprimir la respuesta inflamatoria inducidas por estas citocinas, como la liberación de citocinas proinflamatorias, quimiocinas, IgE y FeNO. ${ }^{9,10}$

En estudios clínicos fases $2 \mathrm{~b}^{11}$ y $3^{12,13,14}$ en adolescentes mayores a 12 años y adultos con asma moderada y grave, el tratamiento subcutáneo con 200 o $300 \mathrm{mg}$ de dupilumab cada dos semanas por hasta 52 semanas mostró sostenidamente niveles reducidos de $\mathrm{FeNO}^{11,13,15,16}$ y otros biomarcadores de inflamación tipo 2, incluyendo niveles séricos de IgE, quimiocina tímica regulada por activación, eotaxina-3/periostina; ${ }^{12,15,17}$ al compararse versus placebo $(\mathrm{p}<0.001)$. La supresión de estos biomarcadores es estadísticamente significativa después de dos semanas de tratamiento con dupilumab ${ }^{11,13,18}$ (con excepción de IgE, para cual fue más lenta la disminución ${ }^{15}$ ) y se mantuvo un decremento sostenido durante todo el tratamiento. ${ }^{7,8,11,13,16,19}$ Fue evidente un beneficio similar con estas dosis de dupilumab en pacientes con asma con o sin enfermedad alérgica concomitante, tal como rinitis alérgica o rinosinusitis crónica con poliposis nasal ${ }^{17}$ que se evidencia en el análisis post hoc del estudio QUEST. Dupilumab redujo la infiltración pulmonar de EOS, disminuyó la metaplasia de células caliciformes y mejoró la función pulmonar en un modelo animal murino 


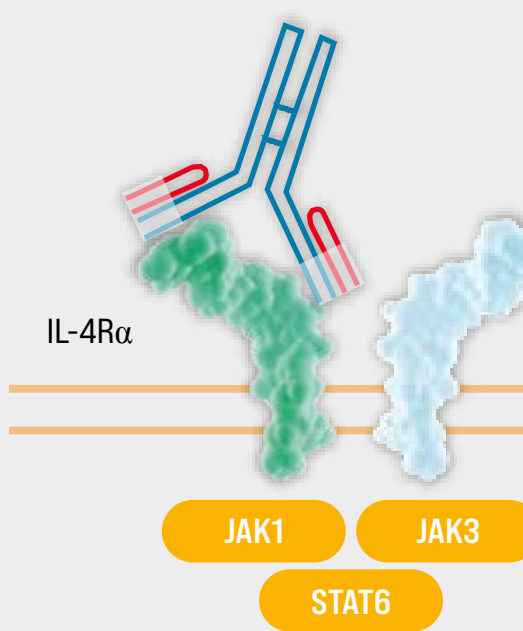

Receptor tipo 1

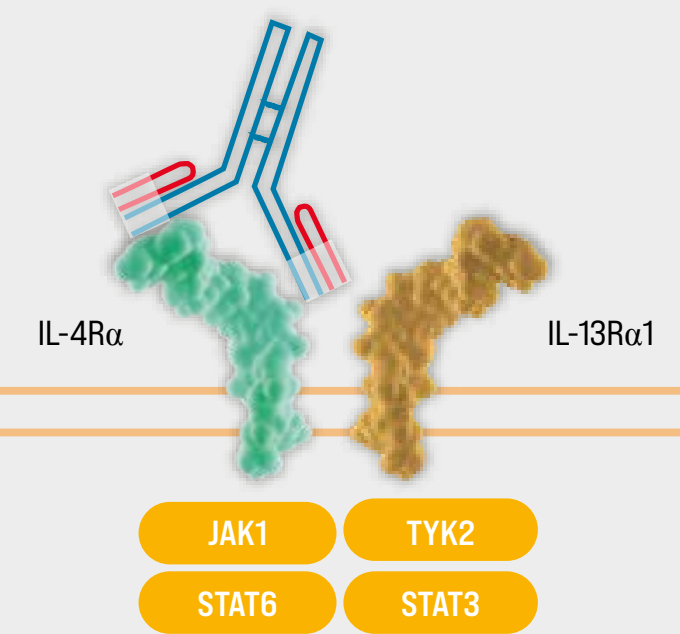

Receptor tipo 2

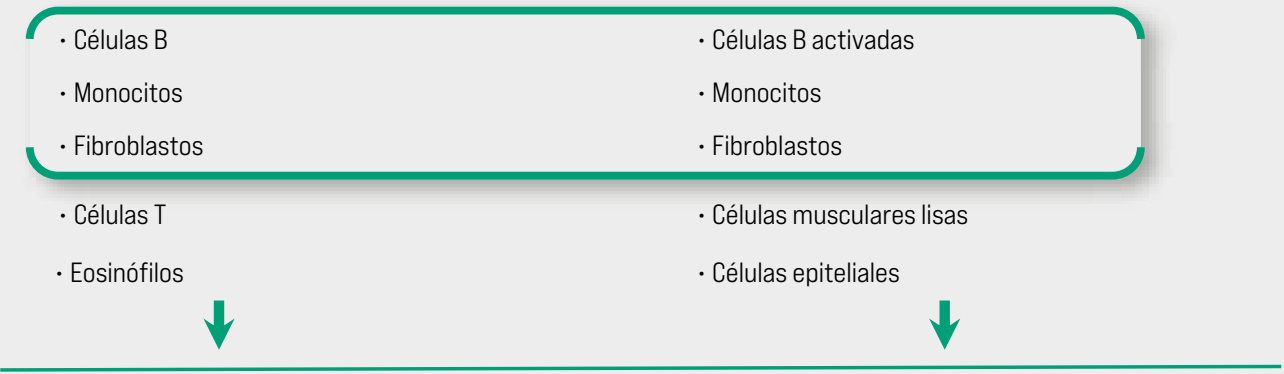

Expresión de citocinas y quimiocinas de tipo 2 con activación de mediadores proinflamatorios

Figura 3. Dupilumab es un inhibidor dual de la señalización de IL-4 e IL-13, las cuales tienen en común una subunidad del receptor, IL-4R $\alpha^{7}$ Dupilumab es un anticuerpo monoclonal lgG4 recombinante que inhibe la acción de IL-4 e IL-13. ${ }^{65}$ Dupilumab inhibe IL-4 vía el receptor tipo I [LL-4R $\left.\alpha / \gamma c\right]$ y la señalización de IL-4 e IL-13 mediante el receptor de tipo II [IL-4R $\alpha / I L-13 R \alpha] .^{65}$ Las rutas de señalización IL-4 e IL-13 tienen funciones únicas y sobrepuestas. ${ }^{1,65}$ IgG = inmunoglobulina G, IL = interlucina, IL-4R $\alpha$ = receptor de interlucina 4 alpha, IL-13R $\alpha 1=$ receptor de interlucina 13 alpha 1 , JAK = cinasas Jano, STAT = transductor de señal y activador de la transcripción, TYK = tirosincinasa.

de inflamación tipo 2 inducida por alérgeno. ${ }^{20}$ Aunque los pacientes con asma tuvieron aumentos transitorios en el recuento de EOS séricos tras iniciar el tratamiento con dupilumab, las elevaciones fueron generalmente sin consecuencias clínicas o eventos adversos y los recuentos de EOS volvieron al nivel basal después de 52 semanas de tratamiento, fenómeno que se explica por el mecanismo de acción del agente biotecnológico. ${ }^{15}$ Se observó un fenómeno similar con dupilumab en pacientes con un recuento basal de EOS en sangre $\geq 300$ / $\mu \mathrm{L}$ en el estudio DRI12544. ${ }^{11}$ En este tenor, en la sección de seguridad se discutirá la eosinofilia. Algunos pacientes tratados con dupilumab pueden desarrollar anticuerpos antidroga (AAD), ${ }^{7,8,13,15}$ por ejemplo, en el estudio QUEST, los anticuerpos estuvieron presentes en el 4.2 y $2.1 \%$ de los pacientes con asma que recibieron 200 y $300 \mathrm{mg}$ cada dos semanas de dupilumab, respectivamente. ${ }^{12}$ Sin embargo, los títulos de AAD son generalmente bajos y no afectan la exposición, eficacia ni seguridad del agente biotecnológico. ${ }^{7,8}$ 


\section{Farmacocinética}

Dupilumab administrado de forma subcutánea exhibe una farmacocinética de distribución media no lineal. ${ }^{7,21}$ Las concentraciones mínimas de dupilumab son más bajas en sujetos con mayor peso corporal, pero el ajuste de la dosis basado en el peso no parece ser necesario en adultos. ${ }^{22}$ La edad y el sexo no parecen afectar la farmacocinética de dupilumab de una forma clínicamente relevante. ${ }^{7}$ No se ha estudiado el efecto de la insuficiencia hepática o renal en la farmacocinética de dupilumab; sin embargo, no se espera una eliminación hepática o renal significativa. ${ }^{7,23}$ Un análisis farmacocinético poblacional en pacientes adultos y adolescentes describió adecuadamente una saturación lineal y no lineal paralela a un modelo de eliminación de Michaelis-Menten más una absorción de primer orden. ${ }^{22,24}$ La farmacocinética de dupilumab no se ve afectada por medicamentos que por lo general son administrados conjuntamente en pacientes con asma moderada o grave $^{8}$ y no parece tener impacto clínicamente significativo en la actividad de las enzimas CYP clave (CYP1A2, CYP2C9, CYP2C19, CYP2D6 o CYP3A4) y, por lo tanto, no se espera que afecte a la farmacocinética de agentes coadministrados en el tratamiento. ${ }^{7,8,20}$

\section{Absorción}

Después de una dosis inicial subcutánea de 600 o $400 \mathrm{mg}$, dupilumab alcanzó concentraciones máximas medias \pm desviación estándar de $70.1 \pm 24.1$ o $41.8 \pm 12.4 \mu \mathrm{g} / \mathrm{mL}$, aproximadamente una semana después de la dosis. Las concentraciones estables máximas se lograron alrededor de la semana 16 después de la administración de la dosis inicial de $600 \mathrm{mg}$ y $300 \mathrm{mg}$ cada dos semanas, o en la dosis inicial de $400 \mathrm{mg}$ y $200 \mathrm{mg}$ cada dos semanas. En todos los ensayos clínicos, las concentraciones mínimas promedio \pm desviación estándar en estado estacionario variaron de $60.3 \pm 35.1 \mu \mathrm{g} / \mathrm{mL}$ a $79.9 \pm 41.4 \mu \mathrm{g} / \mathrm{mL}$ para $300 \mathrm{mg}$ administrados cada dos semanas, de $173 \pm 75.9 \mu \mathrm{g} / \mathrm{mL}$ a $193 \pm 77.0 \mu \mathrm{g} / \mathrm{mL}$ para $300 \mathrm{mg}$ administrados semanalmente, y de $29.2 \pm 18.7$ a $36.5 \pm 22.2 \mathrm{mg} / \mathrm{L}$ por $200 \mathrm{mg}$ administrados cada dos semanas. La biodisponibilidad de dupilumab después de una dosis subcutánea es similar entre los pacientes con dermatitis atópica y asma, oscilando entre 61 y $64 \%$. El volumen total de distribución estimado fue de aproximadamente $4.8 \pm 1.3$ L. $^{7,8}$

\section{Eliminación}

La vía metabólica de dupilumab no se ha definido totalmente. Como un anticuerpo inmunoglobulina G4 monoclonal humano, se espera que dupilumab se degrade en péptidos y aminoácidos pequeños a través de vías catabólicas de la misma manera que la inmunoglobulina $\mathrm{G}$ endógena. Después de la última dosis en concentraciones estables de $300 \mathrm{mg}$ cada dos semanas, $300 \mathrm{mg}$ cada semana o $200 \mathrm{mg}$ cada dos semanas de dupilumab, el tiempo medio de concentración no detectable $(<78 \mathrm{ng} / \mathrm{mL})$ fue de 10 a 11 , 13 y 9 semanas, respectivamente. ${ }^{7,22}$

\section{Eficacia terapéutica de dupilumab}

En pacientes con asma, los efectos terapéuticos de dupilumab se evaluaron por primera vez en un ensayo de fase 2a realizado en 104 pacientes (con rango de edad entre los 18 y 65 años) con asma persistente, con una clasificación de la enfermedad de moderada a grave, asociada a eosinofilia cuantificada tanto en vía aérea o en sangre. ${ }^{13}$ La media basal en el volumen espiratorio forzado en el primer segundo (FEV1) fue del $72 \%$ del valor 
predicho, y los recuentos de EOS fue de al menos 300 células/ $\mu \mathrm{L}$ en niveles séricos o al menos de $3 \%$ en pruebas de esputo inducido. La terapia estándar de estos pacientes se basó en dosis medias o altas de corticosteroides inhalados (CEI) más beta 2 agonistas adrenérgicos de acción prolongada (LABA), que no fueron suficientes para proporcionar un control adecuado del asma en los sujetos estudiados. ${ }^{13}$ Semanalmente 52 pacientes recibieron dosis subcutáneas de $300 \mathrm{mg}$ de dupilumab y 52 pacientes fueron tratados con placebo. Dupilumab fue administrado durante 12 semanas o hasta que los pacientes experimentaron exacerbación del asma. ${ }^{11} \mathrm{El}$ tratamiento con LABA fue suspendido después de cuatro semanas y la terapia con CEI disminuyó gradualmente para luego ser interrumpida entre la sexta y novena semana. El objetivo principal del estudio fue la evaluación de los efectos de dupilumab sobre las exacerbaciones de la enfermedad. Tres individuos que recibieron dupilumab (6\%) y 23 pacientes en el grupo placebo (44\%) tuvieron una exacerbación. Esta evaluación comparativa mostró que dupilumab disminuyó en $87 \%$ la presentación de exacerbaciones del asma $(\mathrm{p}<0.001)$. Respecto a los objetivos secundarios del ensayo clínico, dupilumab aumentó el FEV1 en más de $200 \mathrm{~mL}$ y también mejoró el flujo espiratorio pico máximo de la mañana. Dupilumab también mostró mejoría en referencia a la puntuación del Cuestionario de Control del Asma, en síntomas diurnos y nocturnos, y en necesidad de broncodilatadores de acción corta como medicamentos de rescate. ${ }^{10}$ Además, dupilumab redujo significativamente $(\mathrm{p}<0.001)$ algunos biomarcadores inflamatorios asociados a respuesta tipo 2, incluyendo FeNO, cuya reducción persistió incluso en la semana 12, a pesar del retiro de CEI. También fueron reportadas disminuciones paralelas en otros biomarcadores como las concentraciones sanguíneas de IgE, eotaxina-3 y quimiocina tímica regulada por activación. ${ }^{10,25}$

En otro ensayo clínico fase $2 b^{26}$ realizado en pacientes con asma persistente no controlada, con dosis medias a altas de combinaciones de CEI/LABA que no se interrumpieron durante la terapia complementaria con dupilumab reveló resultados más concluyentes. El ensayo clínico fue subdividido cronológicamente en tres secciones, incluida una fase de detección (de 14 a 21 días), una de tratamiento aleatorizado (24 semanas) y una de tratamiento posterior (16 semanas de seguimiento); fueron asignados aleatoriamente 776 sujetos a cinco grupos: placebo $(\mathrm{n}=158), 200 \mathrm{mg}$ de dupilumab cada dos o cuatro semanas $(\mathrm{n}=150 \mathrm{y} \mathrm{n}=154)$, o $300 \mathrm{mg}$ de dupilumab cada dos o cuatro semanas $(\mathrm{n}=157 \mathrm{en}$ cada uno). Con excepción del grupo que recibió $200 \mathrm{mg}$ cada cuatro semanas, cuando se realizó comparación con el placebo, todas las dosis de dupilumab indujeron aumentos significativos del FEV1, en la semana 24 de 0.15 a $0.16 \mathrm{~L} ;{ }^{11}$ además, cuando se administró cada dos semanas, dupilumab redujo significativamente las tasas anualizadas de exacerbaciones del asma. Todos los regímenes de dupilumab también indujeron disminuciones significativas de la FeNO dependiendo de la dosis, ${ }^{19,27}$ que fueron mayores cuando se recibió el medicamento cada dos semanas. Respecto a la función pulmonar, exacerbaciones de asma y niveles de la FeNO no se detectaron diferencias significativas entre los pacientes que tenían 300 o menos $\mathrm{EOS} / \mu \mathrm{L}$ en sangre periférica. ${ }^{19}$

En general, los eventos adversos fueron similares en los cinco grupos de estudio e incluyeron principalmente infecciones del tracto respiratorio superior, eritema y dolor de cabeza. Fueron reportados aumentos transitorios de EOS en sangre en pacientes con recuentos basales de eosinófilos de al menos 300/ $\mu \mathrm{L} .{ }^{11}$ Por lo tanto, el ensayo mostró que dupilumab fue bien tolerado, con efectos clínicos sobre la función pulmonar y efecto antiinflamatorio relevante, independientemente de los niveles de eosinófilos en sangre.

Debido a que dupilumab resultó ser más efectivo cuando se administró cada dos semanas, este intervalo entre aplicaciones subcutáneas se eligió para evaluar la eficacia del medicamento en ensayos clínicos de fase 3. En particular, el estudio QUEST ${ }^{12}$ evaluó 
pacientes $\geq 12$ años con asma persistente no controlada. VENTURE ${ }^{13}$ tuvo como objetivo verificar el efecto de dupilumab sobre el uso de corticosteroides orales en sujetos con asma grave dependientes de esteroides.

Los ensayos clínicos fase 3 fueron doble ciego controlados con placebo, con períodos de tratamiento aleatorizados de 24 a 52 semanas de duración que evaluaron la eficacia de dupilumab en adultos y adolescentes con asma de moderada a grave $o$ asma grave y de difícil control. Estos estudios fase 3 (QUEST ${ }^{15}$ y VENTURE ${ }^{13}$ ) fueron diseñados principalmente para evaluar las diferencias en las exacerbaciones del asma o la función pulmonar y requirieron que los pacientes tuvieran asma que hubiese empeorado en el último año (resultando en hospitalización o visita a los servicios de urgencias o terapia con CEO (corticosteroides sistémicos orales) y CEI de dosis media a alta más medicamentos de control adicionales.

El estudio VENTURE ${ }^{13}$ evaluó la continuidad o necesidad de CEO y requirió que los pacientes necesitaran regularmente estos fármacos en los últimos seis meses, dosis altas de CEI y hasta dos medicamentos controladores en un periodo de tres o más meses previos al estudio. Antes de la aleatorización, los pacientes de VENTURE tenían una dosis habitual de CEO, la cual durante tres a 10 semanas fue ajustada a la dosis mínima capaz para controlar los síntomas. Esta fase de optimización de CEO fue seguida por un periodo de tratamiento aleatorizado de 24 semanas que constó de tres partes: ${ }^{13}$

- Fase de inducción (semanas 0 a 4), durante la cual los pacientes (distribuidos aleatoriamente) recibieron dosis optimizada de CEO.

- Fase de reducción de CEO (semanas 4 a 20), durante la cual se redujo la dosis de CEO cada cuatro semanas, según los cambios en el control del asma y la incidencia de exacerbaciones (conforme el programa especificado previamente).

- Fase de mantenimiento (semanas 20 a 24), durante la cual la dosis de CEO establecida al final de la fase de reducción se continuó sin cambios.

En todos los estudios, los pacientes tenían una edad de aproximadamente 50 años, una media de FEV1 (prebroncodilatador) de 52 a $61 \%$ del valor predicho, un recuento promedio de eosinófilos séricos de 347 a 360 células/ $\mu \mathrm{L}$ y una media de exacerbaciones graves de 2.1 a 2.2 en el último año. Aproximadamente el $50 \%$ de los pacientes del QUEST $^{15}$ estaba bajo un esquema terapéutico con altas dosis de CEI. Los pacientes de VENTURE ${ }^{13}$ habían recibido su primera receta de CEO en promedio 1.7 años antes y la dosis fue de $11.8 \mathrm{mg} /$ día previo al ajuste.

\section{Exacerbaciones}

El efecto sumatorio del tratamiento con dupilumab logró reducir la tasa de exacerbaciones graves del asma en adultos y adolescentes cuya enfermedad fue controlada de forma inadecuada con CEI en dosis media o alta ${ }^{11,15}$ o que dependía de CEO para el control. ${ }^{13}$ En cuanto a la comparación con placebo, dupilumab (200 o 300 mg cada dos semanas) redujo casi $50 \%$ la tasa anual de estas exacerbaciones por paciente durante 52 semanas en QUEST (objetivo primario); ${ }^{15}$ los resultados de VENTURE ${ }^{13}$ de igual forma apoyan estos hallazgos. Las tasas correspondientes de hospitalizaciones o visitas a la sala de urgencias por exacerbaciones graves mostraron también una disminución de casi el $50 \%$ con dupilumab respecto a placebo en QUEST (46.8 \% para dosis combinadas); ${ }^{15}$ un análisis agrupado de QUEST y DRI12544 (estudio fase 2b) reportó reducciones del 25.5 y $46.9 \%$ con 200 y $300 \mathrm{mg}$ de dupilumab cada dos semanas. ${ }^{8}$ 


\section{Semana 52 [ITT], fase 3 [QUEST]}

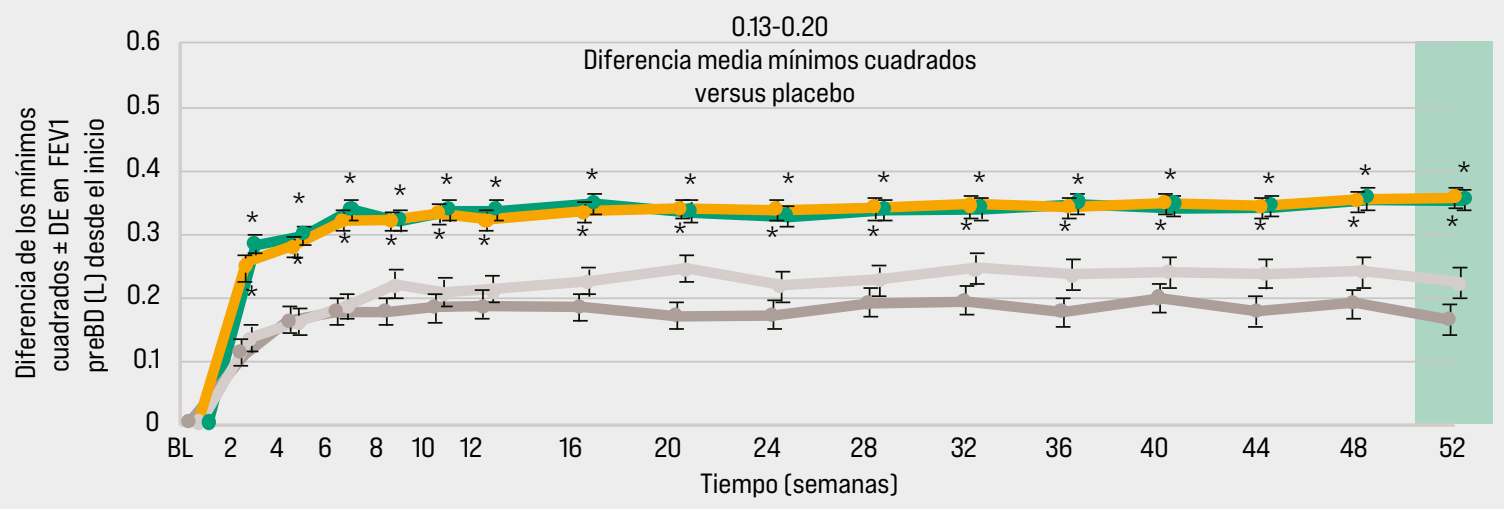

Placebo $200 \mathrm{mg} \mathrm{c} / 2$ semanas [media basal FEV1 = 1.76 L; ITT, $\mathrm{n}=240-317$ ]

17. Placebo $300 \mathrm{mg} \mathrm{c} / 2$ semanas [media basal FEV1=1.75 L; ITT, $\mathrm{n}=250-321$ ]

Dupilumab $200 \mathrm{mg} \mathrm{c} / 2$ semanas [media basal FEV1 = 1.78 L; ITT, $n=477-631$ ]

- Dupilumab $300 \mathrm{mg} \mathrm{c} / 2$ semanas (media Basal FEV1=1.78 L; ITT, $n=488-633$ ]

Figura 4. Dupilumab demostró diferencias significativas y mejoría rápida en la función pulmonar, que se mantuvo tras 52 semanas de tratamiento. Es probable que los cambios en el FEV1 de 0.1 a 0.2 L sean clínicamente importantes (conforme se indicó en un taller de trabajo de los Institutos Nacionales de Salud de Estados Unidos]. * $\mathrm{p}<0.001, \mathrm{DE}=$ desviación estándar, FEV1 = volumen espiratorio forzado en el primer segundo, ITT = intención de tratar, $\mathrm{LS}=$ mínimos cuadrados.

\section{Función pulmonar y uso de corticosteroides}

Dupilumab mejoró la función pulmonar con cada dosificación (200 o 300 mg cada dos semanas) en todos los estudios, demostrándose aumento significativo en el FEV1 versus placebo durante el tratamiento de 12 semanas $^{11,16}$ (objetivo primario), mismo que se mantuvo durante 24 y 52 semanas (figuras 4 y 5). Este parámetro mejoró significativamente después de solo dos semanas de tratamiento con dupilumab en todos los ensayos $(\mathrm{p}<0.001 \text { versus placebo })^{12,13,16}$ y generalmente fue respaldado por otras evaluaciones de la función pulmonar, como capacidad vital forzada, flujo espiratorio forzado $25-75 \%$ de la capacidad vital forzada y flujo pico espiratorio máximo por la mañana o tarde (los análisis fueron especificados o se reportaron en el análisis post hoc). ${ }^{15,28,29}$ Además, dupilumab tuvo beneficios de ahorro de CEO en pacientes con dependencia de CEO en VENTURE. ${ }^{13}$ Mientras mantuvo el control del asma, dupilumab (300 mg cada dos semanas) permitió que la dosis diaria de CEO se redujera significativamente en mucho mayor medida que el placebo, reportado en la comparación de la semana 24, es decir, al final de la fase de mantenimiento con CEO (figura 6). ${ }^{13}$ En análisis similares, dupilumab también ha demostrado proporcionar un beneficio significativo versus placebo para objetivos de investigación secundarios clave como el ahorro de CEO, incluida la proporción de pacientes cuya dosis diaria de CEO se redujo a menos de $5 \mathrm{mg}$ (en $50 \%$ o más de los sujetos) por el máximo posible o la proporción que ya no requirió esta medicación. ${ }^{13}$ 


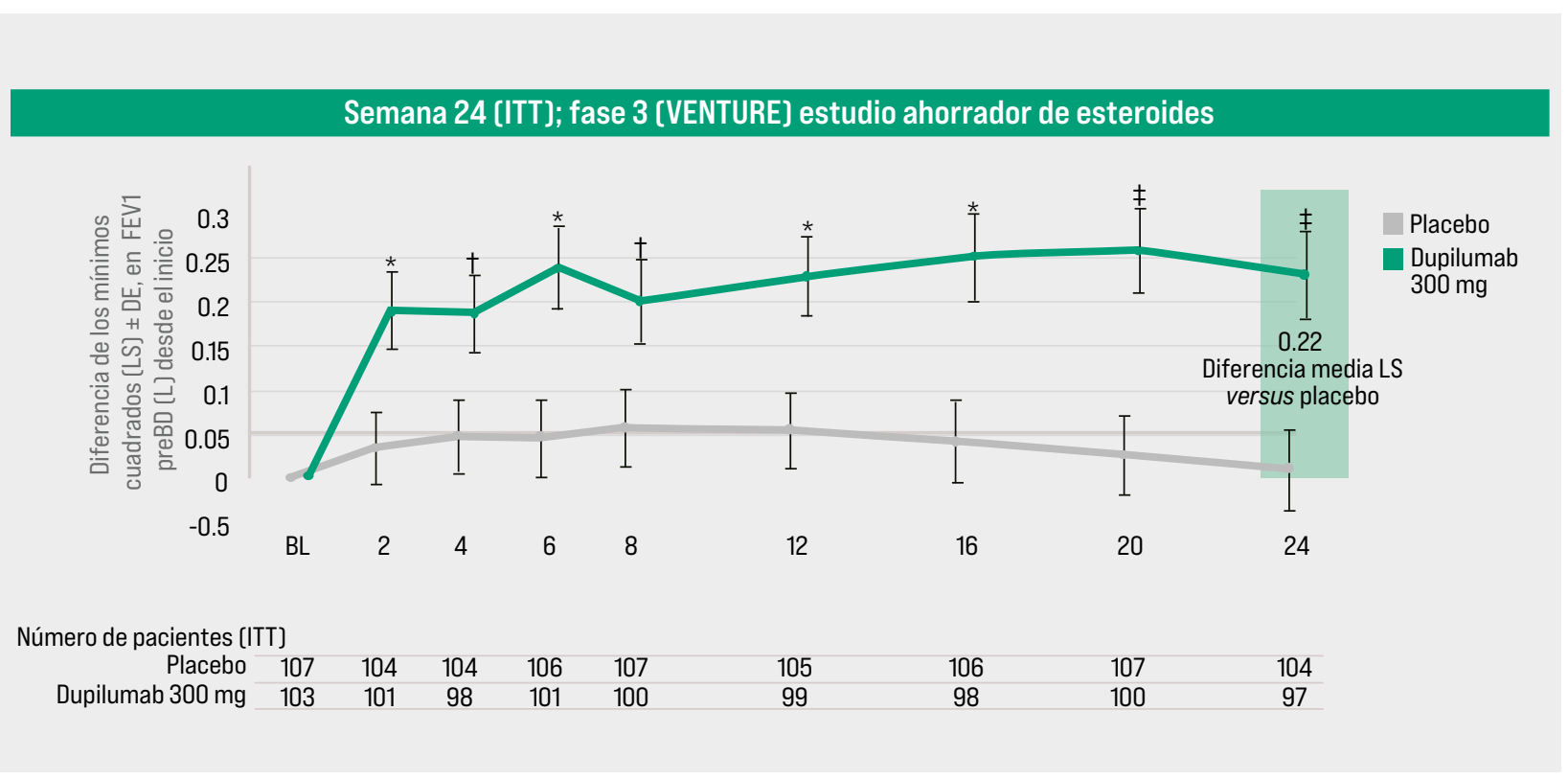

Figura 5. Cambios absolutos en FEV1 prebroncodilatador. Dupilumab demostró mejoría significativa de la función pulmonar, que se mantuvo tras 24 semanas de tratamiento a pesar de la titulación de CEO. Es probable que los cambios en el FEV1 de 0.1 a 0.2 L sean clínicamente importantes (conforme se indicó en un taller de trabajo de los Institutos Nacionales de Salud de Estados Unidos]. ${ }^{*} p<0.01,{ }^{\dagger} p<0.05,{ }^{\ddagger} p<0.001$. DE = desviación estándar, FEV1 = volumen espiratorio forzado en el primer segundo, ITT = intención de tratar, LS = mínimos cuadrados, preBD = broncodilatador.

\section{Otros resultados}

Al igual que con la función pulmonar, la mejoría en el control del asma (evaluado por el Cuestionario de Control de Asma de cinco puntos) fue evidente con dupilumab (200 o $300 \mathrm{mg}$ cada dos semanas) en relación con el placebo desde las dos semanas, ${ }^{15} \mathrm{y}$ así se mantuvo a las $24^{11,13,15}$ y $52^{15}$ semanas en los ensayos clínicos pivotales $(\mathrm{p}<0.01)^{11}$ (figura 7). Además, la calidad de vida relacionada con el asma también evidenció mejoría con cada uno de los regímenes de administración de dupilumab versus placebo, según lo evaluado por el Cuestionario de Calidad de Vida en pacientes con asma, con mejoría en las puntuaciones globales $(\mathrm{p}<0.01) .{ }^{11,15}$ En particular, en un análisis post hoc de DRI12544, los pacientes que recibieron dupilumab lograron una respuesta estadísticamente significativa $(\mathrm{p}<0.05)$ en comparación con los que recibieron placebo, en las evaluaciones de control del asma (73-77\% versus $60-61 \%$ ) y en la calidad de vida relacionada con el asma (61-65 \% versus $48-51 \%$ ) en la semana 24 , así como mejora en las puntuaciones de 0.5 o 0.6 o más en el Cuestionario de Control de Asma de cinco puntos y en el Cuestionario de Calidad de Vida en pacientes con asma. ${ }^{26}$ La productividad laboral también mejoró con dupilumab en este análisis, con una tasa anualizada no ajustada de seis días de ausentismo por exacerbaciones graves, la cual fue significativamente menor con 200 o $300 \mathrm{mg}$ de dupilumab versus placebo (0.61 y 0.62 versus $2.24 ; \mathrm{p}<0.0001){ }^{26}$

\section{Eficacia de dupilumab respecto a la inflamación tipo 2}

En los estudios fases 2 y 3 de dupilumab, ${ }^{11,13,15}$ se realizó un subanálisis de los resultados, tomando como base los biomarcadores de inflamación tipo 2, entre los que destacan los niveles de la FeNO y la cuenta de EOS en sangre; los pacientes fueron incluidos 
independientemente de los valores basales de estos biomarcadores. ${ }^{30}$ Se diferenció entre los pacientes que tuvieron $\mathrm{FeNO}<25 \mathrm{ppb}\left(\mathrm{FeNO}_{<25}\right)$, los que tuvieron $\geq 25 \mathrm{a}<50 \mathrm{ppb}$ $\left(\mathrm{FeNO}_{25-50}\right)$ y los que tuvieron $\geq 50 \mathrm{ppb}\left(\mathrm{FeNO}_{>50}\right) \cdot{ }^{13} \mathrm{En}$ el caso de EOS, los pacientes se estratificaron en aquellos con $<150$ células $/ \mathrm{mm}^{3}\left(\mathrm{EOS}_{<150}\right)$, con $\geq 150 \mathrm{a}<300$ células $/ \mathrm{mm}^{3}\left(\mathrm{EOS}_{150-300}\right)$ y los que tuvieron $\geq 300$ células $/ \mathrm{mm}^{3}\left(\mathrm{EOS}_{>300}\right) .{ }^{15}$

En el estudio QUEST, el análisis de tasa de exacerbaciones de acuerdo con la cuenta basal de EOS mostró diferencias significativas en las dos dosis $(200$ y $300 \mathrm{mg}$ de dupilumab cada dos semanas). En el caso de los pacientes con $\mathrm{EOS}_{>300}$, la tasa fue de 0.37 (0.29-0.48) para la dosis menor de dupilumab versus 1.08 (0.85-1.38) con placebo, mientras que para la dosis mayor fue de $0.40(0.32-0.51)$ versus $1.24(0.97-1.57)$ con placebo, lo que significa una tasa menor en un $67.4 \%$ de exacerbaciones con dupilumab versus placebo $(\mathrm{p}<0.001)$. En el grupo de pacientes con $\mathrm{EOS}_{150-300}$, de igual forma se presentó una tasa menor de exacerbaciones con dupilumab versus placebo: $0.56(0.42-0.75)$ con la dosis menor de dupilumab versus 0.87 (0.59-1.27) con placebo, y $0.47(0.35-0.64)$ con la dosis mayor versus $0.84(0.58-1.23)$ con placebo. ${ }^{12} \mathrm{La}$ tasa de exacerbaciones entre dupilumab versus placebo fue similar en los pacientes del grupo $\operatorname{EOS}_{<150}{ }^{15}$ (figura 8).

Estos resultados se presentan también al analizar los grupos divididos de acuerdo con FeNO. En el mismo estudio QUEST, la tasa de exacerbaciones entre los pacientes tratados con dupilumab respecto a placebo fueron mayores en los pacientes de los grupos $\mathrm{FeNO}_{>50}$ y $\mathrm{FeNO}_{25-50}$ que en aquellos con un valor menor $\left(\mathrm{FeNO}_{<25}\right)$ (figura 9). ${ }^{15,19}$

Ligado a lo anterior, el beneficio de dupilumab respecto a la función pulmonar evaluada con FEV1 prebroncodilatador fue mayor en pacientes con $\mathrm{EOS}_{>300}$. A la semana 12 , el cambio era de $0.43 \mathrm{~L}$ con la dosis menor de dupilumab versus $0.21 \mathrm{~L}$ para el grupo

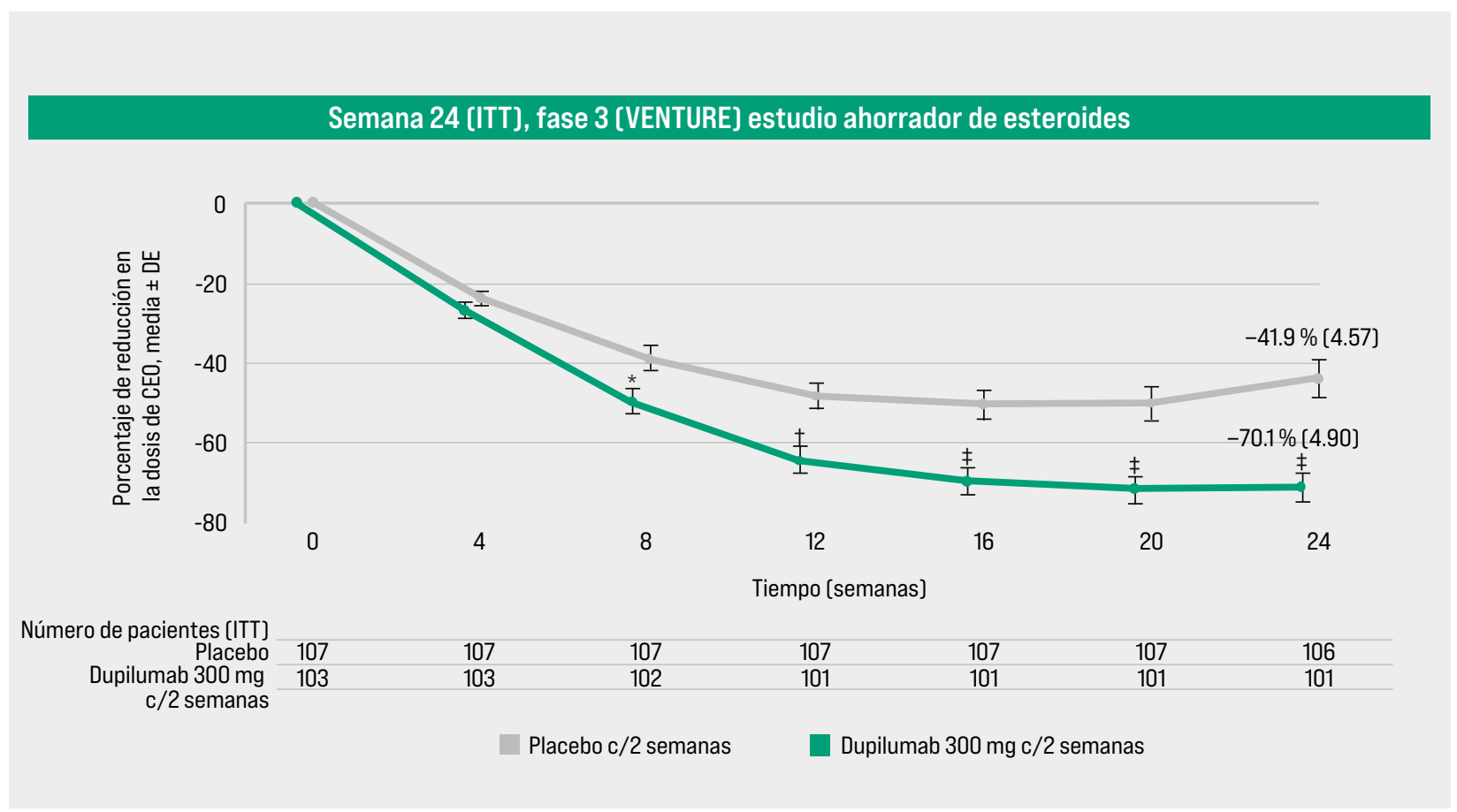

Figura 6. Porcentaje de reducción de la dosis de CEO. Dupilumab redujo significativamente la dosis de CEO mientras mantenía el control del asma versus placebo en la semana 24. ${ }^{\star} p<0.01,{ }^{\dagger} p<0.05,{ }^{\ddagger} p<0.001$. CEO = corticosteroides sistémicos orales, DE = desviación estándar, ITT = intención de tratar. 


\section{Semana 24 (ITT); fase 3 [VENTURE] estudio ahorrador de esteroides}

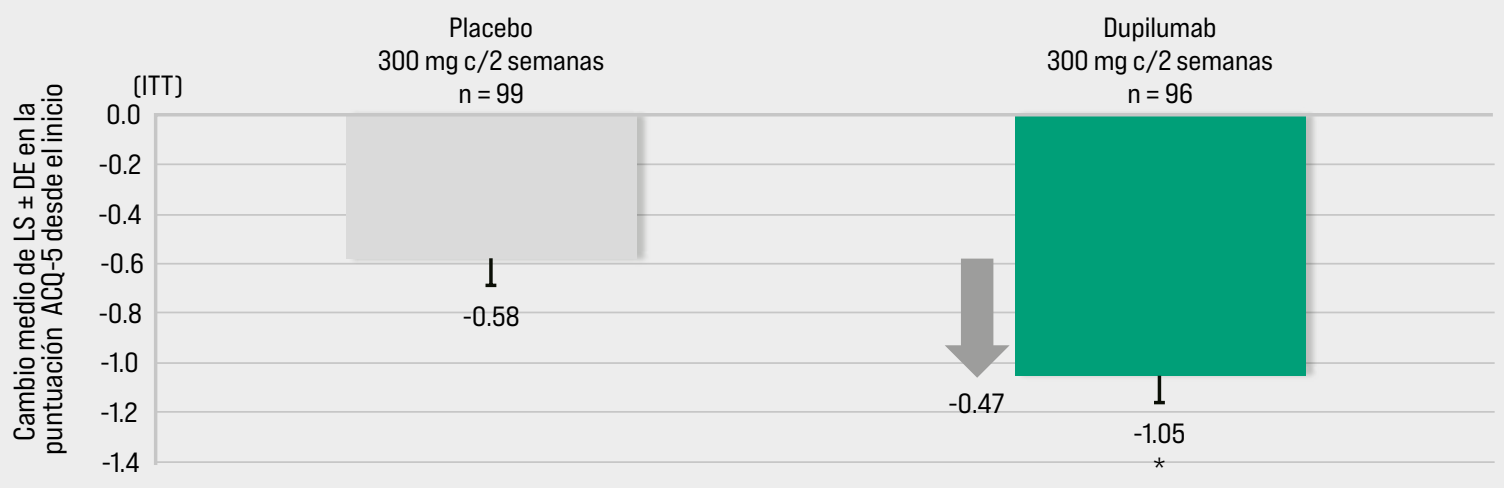

Figura 7. Cambio en la puntuación del ACQ-5. Dupilumab mejoró significativamente el control del asma versus placebo en la población estudiada. * $\mathrm{p}<0.01$. ACQ-5 = Cuestionario de Control de Asma de cinco puntos, DE = desviación estándar, ITT = intención de tratar, LS = mínimos cuadrados.

placebo, con una diferencia de $0.21 \mathrm{~L}(0.13-0.29)$; y $0.48 \mathrm{~L}$ con la dosis mayor de dupilumab versus 0.22 con placebo, con diferencia de $0.24 \mathrm{~L}(0.16-0.32) .{ }^{31,32}$ Esta misma tendencia se observó, aunque en menor grado, en pacientes del grupo $\mathrm{EOS}_{150-300}$ en quienes el cambio en FEV1 a la semana 12 fue de $0.28 \mathrm{~L}$ con la dosis menor de dupilumab y de $0.17 \mathrm{~L}$ con placebo, con una diferencia de $0.11 \mathrm{~L}(0.01 \text { a } 0.21)^{30,33}$ (figura 10).

Dupilumab tuvo un mayor beneficio en FEV1 a la semana 12 respecto a la medición basal en los pacientes de los grupos $\mathrm{FeNO}_{>50} \mathrm{y} \mathrm{FeNO}_{25-50}$ en comparación con el grupo de $\mathrm{FeNO}_{<25}$. En los pacientes con $\mathrm{FeNO}_{25-50}$, la diferencia comparada con placebo fue de $0.19 \mathrm{~L}(0.09-0.28)$ en la dosis menor de dupilumab y de $0.12 \mathrm{~L}(0.03-0.21)$ con la dosis mayor. ${ }^{13}$ En los pacientes con $\mathrm{FeNO}_{>50}$ la diferencia al comparar con placebo fue de $0.30 \mathrm{~L}(0.17-0.44)$ con la dosis menor de dupilumab y de $0.39 \mathrm{~L}(0.26-0.52)$ con la dosis mayor. ${ }^{17,34}$

En el estudio VENTURE, aunque hubo un cambio mayor en la magnitud del resultado de acuerdo con la cuenta de eosinófilos, el tratamiento con dupilumab se asoció con mayor reducción en el uso de CEO que en el grupo placebo, independientemente de la cuenta total basal de eosinófilos. ${ }^{13}$ La magnitud del efecto fue mayor en pacientes con mayor cuenta basal de eosinófilos. En los pacientes que lograron una reducción de por lo menos un $50 \%$ en la dosis de esteroides orales, la razón de momios para dupilumab versus placebo fue de $6.59(2.13-20.42)$ en los pacientes con $\mathrm{EOS}_{>300} \mathrm{y}$ de $2.91(1.28 \mathrm{a}$ 6.63 ) en aquellos con conteo basal $<300$ eosinófilos $/ \mathrm{mm}^{3} .{ }^{35,36}$ Igualmente, en el estudio VENTURE, el tratamiento con dupilumab resultó en disminución de la tasa anualizada de exacerbaciones graves y mayor FEV1 que con placebo, independientemente de la cuenta basal de eosinófilos; beneficios que fueron más pronunciados en los pacientes con mayor cantidad de eosinófilos séricos y con mayores niveles basales de FeNO. ${ }^{13,37}$

Cuando en QUEST, ${ }^{12,17}$ VENTURE ${ }^{13,39}$ y DRI $12544^{26,38,40}$ se evaluó el impacto de dupilumab en el control del asma (Cuestionario de Control de Asma de cinco puntos) o la calidad de vida relacionada con el asma (Cuestionario de Calidad de Vida en pacientes con asma) con las características del paciente (por ejemplo, historia de exacerbaciones, ${ }^{14,26,38}$ niveles basales de FEV1, ${ }^{14}$ rinitis alérgica ${ }^{30}$ o rinosinusitis crónica 
Semana 52; fase 3 [QUEST]

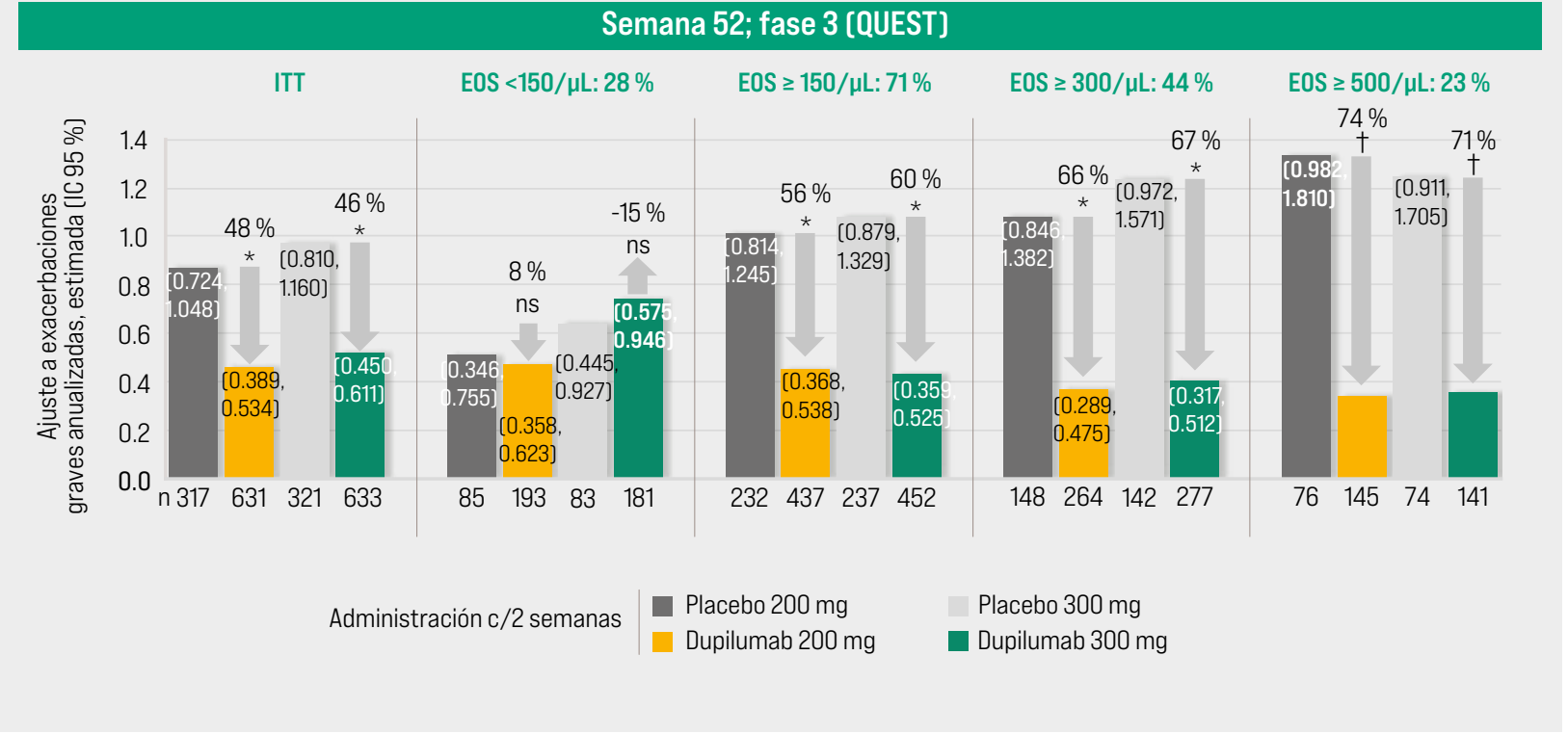

Figura 8. Tasa de exacerbaciones anualizadas graves por niveles basales de EOS. ${ }^{\star} p<0.001,{ }^{\dagger} p<0.05$. IC $=$ intervalo de confianza, EOS $=$ eosinófilos, ITT = intención de tratar, ns = no significativo.

con poliposis nasal) ${ }^{17}$ los resultados fueron consistentes en la disminución de las exacerbaciones y la mejoría de la función pulmonar. Es de destacar que una gran proporción de pacientes tratados con dupilumab con EOS séricos elevados $(\geq 150$ o $300 / \mu \mathrm{L})$ o con niveles de FeNO ( $\geq 25 \mathrm{ppb}$ ) al inicio de los estudios clínicos alcanzaron una mejoría en el Cuestionario de Control de Asma de cinco puntos (70-76 \% versus $64-67 \%$ en pacientes con placebo) o en el Cuestionario de Calidad de Vida en pacientes con asma (62-71 \% versus 53-59\%), con mejoría en la puntuación $\geq 0.5$, después del tratamiento de 52 semanas en QUEST. ${ }^{12}$ Además, los pacientes de QUEST ${ }^{17,41}$ y VENTURE ${ }^{42}$ que tuvieron comorbilidad con rinitis alérgica ${ }^{41}$ o rinosinusitis crónica ${ }^{41,42}$ mostraron mejoría ( $\mathrm{p} \leq 0.05$ versus placebo) en las medidas de calidad de vida relacionada con el asma respecto a las comorbilidades (en el Cuestionario de Calidad de Vida de Rinoconjuntivitis ${ }^{41}$ y el 22-Item Sinonasal Outcome Test) ${ }^{34,42}$ siendo consistente el resultado de dupilumab en todos los puntos de tiempo evaluados (12, 24 y 52 semanas); los datos de los subgrupos de pacientes con rinitis alérgica concomitante de DRI12544 apoyan el beneficio de dupilumab al respecto. ${ }^{43}$ Los análisis fueron especificados previamente ${ }^{41,42} \mathrm{o}$ reportados post hoc, ${ }^{17,26,27,30,40}$ donde se evidenciaron dichas especificaciones.

\section{Seguridad de dupilumab}

Dupilumab, administrado por vía inyección subcutánea sumado a la terapia de mantenimiento inhalada durante 24 o 52 semanas fue generalmente bien tolerado en adultos y adolescentes con asma de moderada a grave en los tres ensayos clínicos discutidos (QUEST, ${ }^{15}$ VENTURE ${ }^{13}$ y DRI12544 ${ }^{11}$ ); su perfil de seguridad en estos puntos de evaluación fue generalmente similar. ${ }^{15}$ En los tres estudios, el perfil de seguridad (200 y $300 \mathrm{mg}$ cada dos semanas) fue similar al de placebo respecto a la incidencia de eventos 


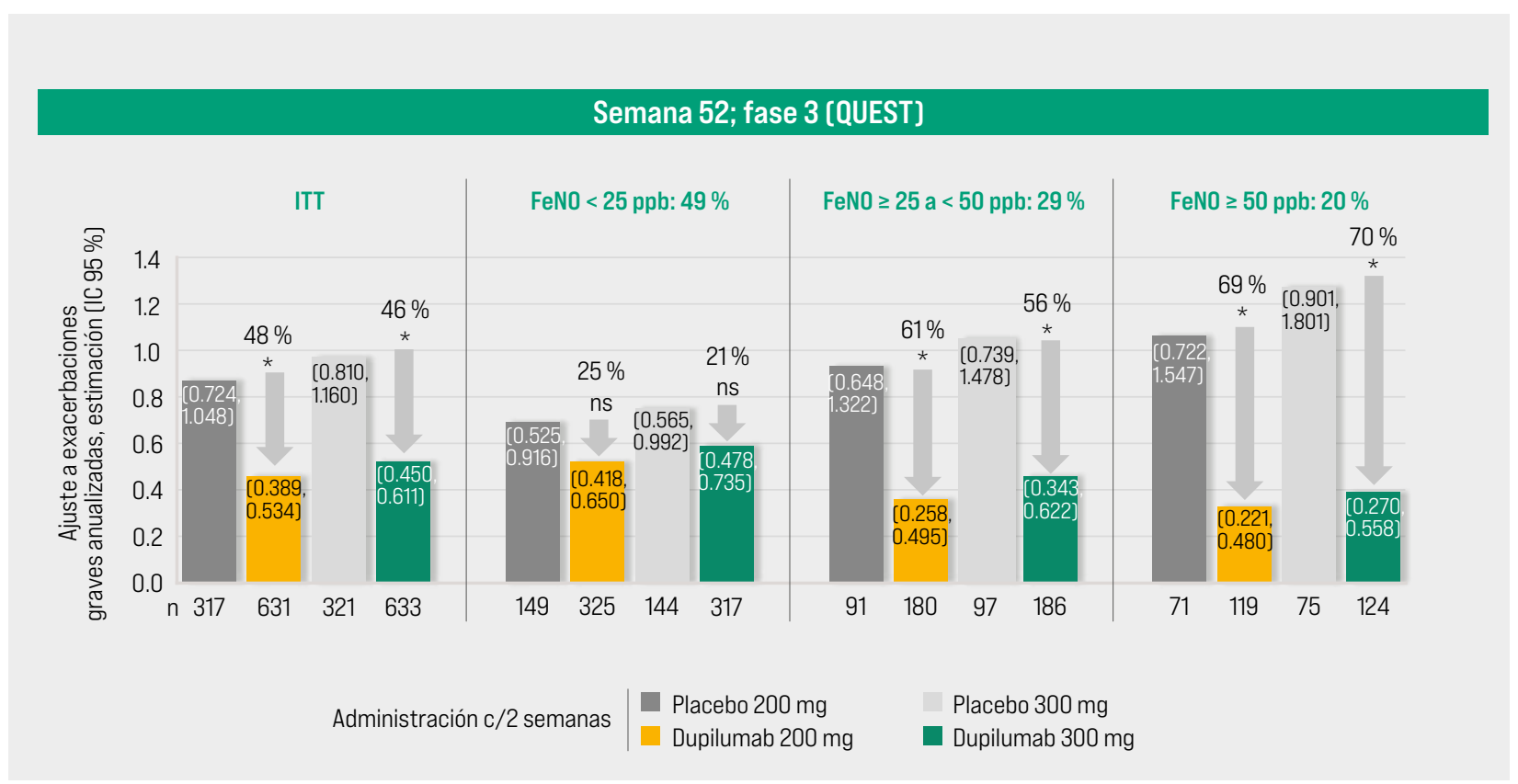

Figura 9. Tasa de exacerbaciones anualizadas graves por niveles basales de FeNO. ${ }^{\star} p<0.001$. IC = intervalo de confianza, FeNO = fracción exhalada de óxido nítrico, ITT = intención de tratar, ns = no significativo.

adversos (62-82 \% versus 64-84\%), eventos adversos graves (7-9 \% versus 6-8 \%), efectos adversos que ocasionaron la interrupción del tratamiento (1-7 \% versus 3-6\%) o muerte $(0-0.6 \%$ versus $0-1 \%) .{ }^{11,13,15}$

El cuadro 1 resume las reacciones adversas que ocurrieron en al menos $1 \%$ de los sujetos tratados con dupilumab y a una proporción mayor que sus respectivos grupos de comparación.

\section{Reacciones adversas específicas}

\section{Conjuntivitis}

Entre los sujetos con asma, la frecuencia de conjuntivitis fue similar entre dupilumab versus placebo y no se encontraron diferencias significativas entre estos grupos. A diferencia de lo observado en los estudios pivotales sobre dermatitis atópica, actualmente no se observa este fenómeno en mayor medida que en asma, lo cual sugiere que el mecanismo implicado es inherente a la enfermedad (dermatitis atópica). ${ }^{13,16,44}$

\section{Eosinofilia}

Los sujetos tratados con dupilumab tuvieron una media inicial mayor de incremento a partir del registro basal en la cuenta de eosinófilos en sangre, en comparación con los sujetos tratados con placebo. En los sujetos con asma, la media y la mediana de los incrementos de los eosinófilos en sangre desde el comienzo hasta la semana 4 fueron de 130 y 10 células $/ \mu \mathrm{L}$, respectivamente. ${ }^{7,8,20} \mathrm{La}$ incidencia de eosinofilia surgida durante el tratamiento ( $\geq 500$ células $/ \mu \mathrm{L}$ ) fue similar en los grupos de dupilumab y placebo. La eosinofilia surgida durante el tratamiento ( $\geq 5000$ células/ $\mu \mathrm{L}$ ) fue reportada en más de $2 \%$ de los pacientes 
Cuadro 1. Indicaciones aprobadas y recomendaciones de dosificación para dupilumab subcutáneo en regiones globales [Food and Drugs Administration, European Medicines Agency y Japón]

\begin{tabular}{|c|c|c|}
\hline Región & Indicación & Dosis recomendada \\
\hline Europa & $\begin{array}{l}\text { Tratamiento de mantenimiento adicional para el } \\
\text { asma grave con inflamación tipo } 2 \text { [caracterizada } \\
\text { por aumento de EOS en sangre o FeNO elevado] en } \\
\text { adolescentes y adultos controlados de manera } \\
\text { inadecuada con dosis altas de CEI más otro } \\
\text { tratamiento de mantenimiento. }\end{array}$ & $\begin{array}{l}600 \text { mg de dosis de carga y despues } 300 \text { mg cada } \\
\text { dos semanas en pacientes con asma grave y CEO } \\
\text { o con asma grave y dermatitis atópica moderada a } \\
\text { severa como comorbilidad. } \\
400 \text { mg dosis de carga y después } 200 \text { mg cada dos } \\
\text { semanas en todos los demás pacientes. }\end{array}$ \\
\hline $\begin{array}{l}\text { Estados Unidos/ } \\
\text { México* }\end{array}$ & $\begin{array}{l}\text { Tratamiento de mantenimiento complementario en } \\
\text { pacientes } \geq 12 \text { años de edad, con asma de moderada } \\
\text { a grave fenotipo eosinofílico o con asma dependien- } \\
\text { te de CEO.* }\end{array}$ & $\begin{array}{l}600 \text { mg de dosis de carga y después } 300 \text { mg cada } \\
\text { dos semanas [régimen inicial recomendado para pa- } \\
\text { cientes con asma dependiente de CEO o con derma- } \\
\text { titis atópica moderada a grave como comorbilidad]. } \\
400 \text { mg de dosis de carga y después } 200 \text { mg cada } \\
\text { dos semanas en caso de no existencia de enferme- } \\
\text { dad por inflamación tipo 2.* }\end{array}$ \\
\hline Japón & $\begin{array}{l}\text { Tratamiento complementario en pacientes de edad } \\
\geq 12 \text { años con asma bronquial grave o intratable que } \\
\text { no se controla con el tratamiento existente que tie- } \\
\text { nen biomarcadores apropiados de inflamación tipo } 2\end{array}$ & $\begin{array}{l}600 \text { mg de dosis de carga y luego } 300 \text { mg cada dos } \\
\text { semanas }\end{array}$ \\
\hline
\end{tabular}

tratados con dupilumab y en menos de $0.5 \%$ de los pacientes tratados con placebo. La cuenta de eosinófilos en sangre declinó hasta cerca de niveles basales durante el tratamiento. ${ }^{16} \mathrm{La}$ eosinofilia que se observó en los pacientes tratados con dupilumab fue transitoria y no provocó cambios en la terapia base o descontinuación en los estudios pivotales ni incremento en la presentación de gravedad de la enfermedad, algo importante dado que el mecanismo de acción, la producción y activación eosinofílica de la médula ósea es íntegra, lo cual tampoco favoreció un incremento en las infecciones parasitarias. ${ }^{13,16}$

\section{Seguridad cardiovascular}

En el estudio controlado con placebo de un año en sujetos con asma, eventos tromboembólicos cardiovasculares (muertes cardiovasculares, infartos de miocardio no fatales y accidentes cerebrovasculares no fatales) fueron reportados en un paciente $(0.2 \%)$ del grupo con $200 \mathrm{mg}$ de dupilumab cada dos semanas, en cuatro (0.6 \%) del grupo con $300 \mathrm{mg}$ de dupilumab cada dos semanas y en dos $(0.3 \%)$ del grupo placebo. ${ }^{7,11}$

Inmunogenicidad

Como sucede con todas las proteínas terapéuticas, existe el potencial de inmunogenicidad. La detección de formación de anticuerpos es altamente dependiente de la sensibilidad y especificidad del ensayo. Adicionalmente, la incidencia observada de AAD en un ensayo puede estar influida por diversos factores, incluyendo la metodología del ensayo, el manejo de muestras, el momento de recolección de muestras, los medicamentos concomitantes y las enfermedades subyacentes. 


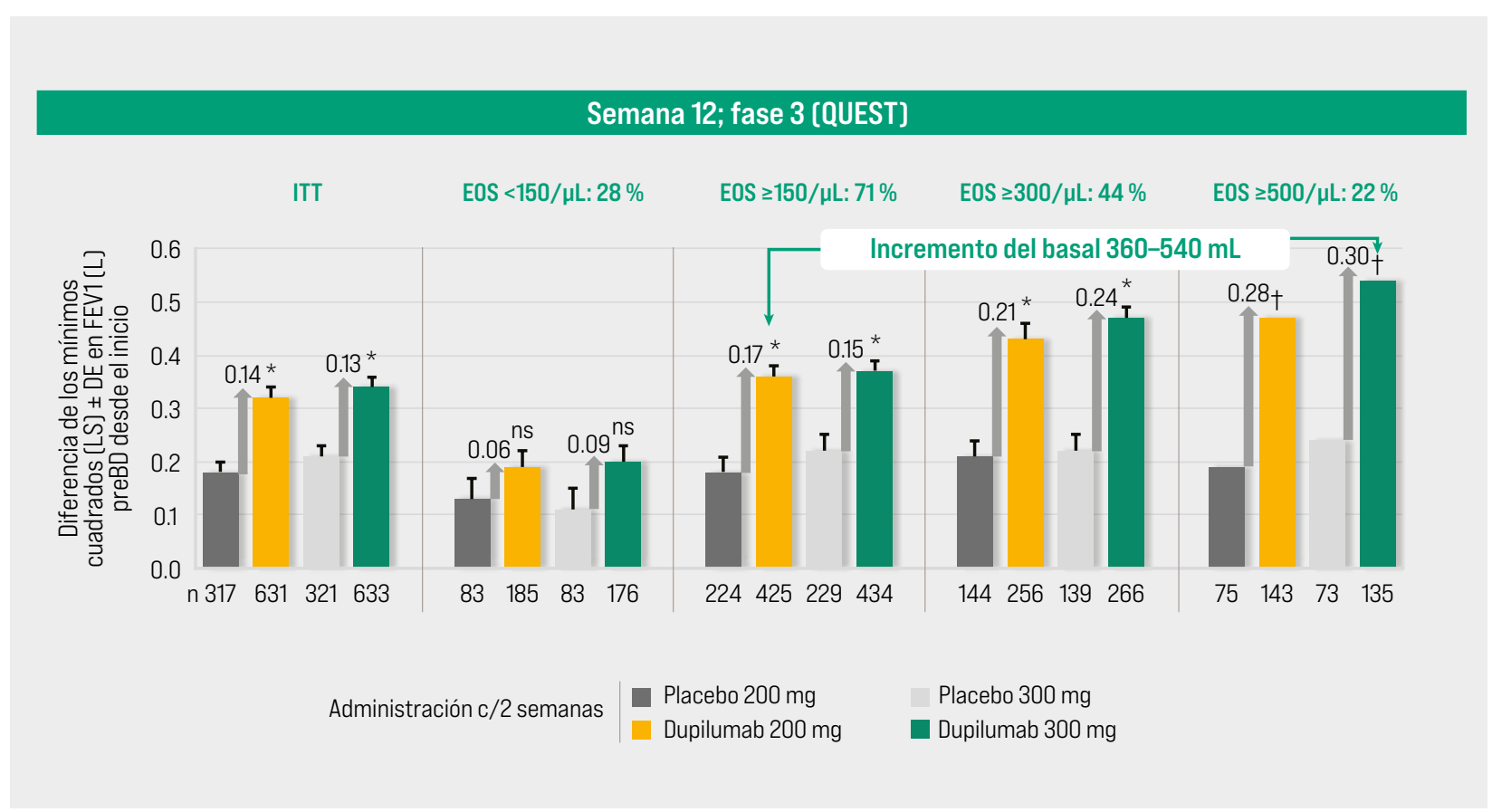

Figura 10. Cambios absolutos en FEV1 prebroncodilatador con niveles basales de EOS. Es probable que los cambios en el FEV1 de 0.1 a $0.2 \mathrm{~L}$ sean clínicamente importantes [conforme se indicó en un taller de trabajo de los Institutos Nacionaels de Salud de Estados Unidos]. ${ }^{*} p<0.001,{ }^{\dagger} p<0.05$. $\mathrm{DE}$ = desviación estándar, EOS = eosinófilos, FEV1 = volumen espiratorio forzado en el primer segundo; ITT = intención de tratar, LS = mínimos cuadrados, preBD = prebroncodilatador, ns = no significativo.

Aproximadamente el $6 \%$ de los sujetos con dermatitis atópica o asma que recibió $300 \mathrm{mg}$ de dupilumab cada dos semanas durante 52 semanas desarrollaron AAD; de este porcentaje, aproximadamente $2 \%$ exhibió respuesta persistente a AAD y aproximadamente $2 \%$ tuvo anticuerpos neutralizantes. ${ }^{7,8}$ Alrededor de $9 \%$ de los sujetos con asma que recibieron $200 \mathrm{mg}$ de dupilumab cada dos semanas durante 52 semanas desarrollaron $\mathrm{AAD}$; de este porcentaje, aproximadamente $4 \%$ exhibió respuestas persistentes a AAD y aproximadamente $4 \%$ tuvo anticuerpos neutralizantes. ${ }^{7,10}$

Los títulos de anticuerpos detectados tanto en los sujetos tratados con dupilumab como con placebo fueron generalmente bajos. En los sujetos que recibieron dupilumab, el desarrollo de un alto título de anticuerpos hacia dupilumab estuvo asociado a una menor concentración sérica de dupilumab. Todavía no se tiene suficiente información si dupilumab (a través de la inhibición de señalización de IL-4/IL-13) podría afectar las respuestas inmunes contra infecciones parasitarias (helmintos). ${ }^{7,8,20}$ Por consiguiente, tales infecciones deben investigarse y tratarse antes de iniciar el anticuerpo monoclonal, aunque si ocurren durante la terapia con dupilumab no se ha visto que el tratamiento antiparasitario afecte el resultado. En general se recomienda suspender dupilumab temporalmente en los pacientes que no respondan al tratamiento. $7,8,20$

\section{Dosis y administración de dupilumab}

Las indicaciones de prescripción para asma en las cuales está aprobado dupilumab en distintas partes del mundo se resumen en el cuadro 2 , en el que se especifican las dosis 
recomendadas y los detalles de administración. Dupilumab puede ser administrado por el propio paciente, el cuidador (después de la capacitación adecuada) o el profesional de la salud a través de inyección subcutánea en el muslo, abdomen o cara lateral superior del brazo (especialmente si es administrado por alguien que no sea el paciente), cambiando de preferencia el sitio de inyección. 7,8,20 Dupilumab debe inyectarse por lo menos a $5 \mathrm{~cm}$ de distancia alrededor del ombligo y debe evitarse su administración en caso de que la piel este erosionada o con excoriaciones, con signos de cicatrización, con presente hipersensibilidad en el área o si esta se encuentre gravemente inflamada debido a dermatitis atópica. 7,8,20 Para pacientes que toman de forma concomitantemente CEO y que experimentan una mejoría clínica con dupilumab, la dosis de CEO puede reducirse, ${ }^{8}$ aunque cualquier reducción deberá considerarse después de iniciar dupilumab. 7,8 El tratamiento no debe usarse para resolver síntomas agudos de asma, exacerbaciones, broncoespasmo agudo, crisis asmáticas o estado asmático. ${ }^{7,8}$ La información de la prescripción local debe ser consultada para conocer los detalles sobre la preparación y administración de dupilumab, uso en poblaciones especiales, contraindicaciones y otras advertencias y precauciones.

\section{Lugar de dupilumab en el tratamiento del asma}

Los objetivos clave del tratamiento del asma incluyen reducir la probabilidad de daño o remodelación en las vías respiratorias, las exacerbaciones y los efectos adversos relacionados con los tratamientos o medicamentos $y$, por ende, la carga general de la enfermedad. ${ }^{43,45}$ Por ello, se recomienda un enfoque de tratamiento gradual o escalonado, con una evaluación adecuada en función de la gravedad actual de la enfermedad, haciendo ajustes a partir de la reevaluación constante. ${ }^{46,47}$ Aunque un porcentaje mayoritario de los pacientes alcanza un control de la enfermedad con un esquema de tratamiento habitual $^{48,49}$ (por ejemplo, CEI, combinados o no con LABA, etcétera), algunos pacientes no lo logran. En un número significativo de estos pacientes con presentaciones más graves de asma, las terapias biológicas específicas han sido un avance importante en el tratamiento. ${ }^{2,50}$

La importancia de los agentes biotecnológicos en el asma es particularmente evidente en la reciente guía de la Global Initiative for Asthma, tanto para el asma de difícil control y asma grave, ${ }^{2,51,52,53}$ la cual recomienda que se consideren como tera-

\begin{tabular}{|c|c|c|c|}
\hline Evento adverso [\%] & $\begin{array}{c}\text { Dupilumab } 200 \mathrm{mg} \\
\text { c/2 semanas } \\
\text { [n }=779] \\
\text { Fase } 2 \mathrm{~b}\end{array}$ & $\begin{array}{c}\text { Dupilumab } 300 \mathrm{mg} \\
\text { c/2 semanas } \\
\text { [n }=788] \\
\text { Fase } 3\end{array}$ & $\begin{array}{l}\text { Placebo } \\
{[n=792]}\end{array}$ \\
\hline $\begin{array}{l}\text { Reacciones en sitio de } \\
\text { aplicación* }^{*}\end{array}$ & $111[14 \%]$ & 144 [18 \%] & 50 [6\%] \\
\hline Dolor orofaríngeo & 13 [2 \%] & 19 [2 \%] & $7[1 \%]$ \\
\hline Eosinofilia $^{\dagger}$ & $17[2 \%]$ & 16 [2\%] & $2[<1 \%]$ \\
\hline \multicolumn{4}{|c|}{$\begin{array}{l}\text { Los eventos adversos ocurren en } 1 \% \text { o más de los grupos de dupilumab y son mayores que en el grupo placebo (grupo de seguridad a seis meses]. } \\
\text { *Incluyen eritema, edema, prurito, dolor e inflamación. } \\
\text { †Eosinofilia = eosinófilos en sangre } \geq 3000 \text { células/ } \mu \mathrm{L} \text { o niveles considerados por el investigador como un evento adverso. Ningún paciente cumplió con } \\
\text { los criterios para condiciones eosinofílicas serias. }\end{array}$} \\
\hline
\end{tabular}


pias complementarias en pacientes con asma grave con inflamación tipo 2 que tienen exacerbaciones, control deficiente de los síntomas con altas dosis de CEI más LABA, que presentan biomarcadores de fenotipos eosinofílicos/alérgicos o con necesidad de CEO como terapia de mantenimiento. Varios documentos y guías establecen que la elección del agente biotecnológico inicial más adecuado puede ser seleccionado en función de las características particulares de los biomarcadores de inflamación tipo 2 $\mathrm{y}$ teniendo en cuenta factores que pueden predecir una buena respuesta al mismo ${ }^{51,53}$ o en relación a factores clínicos que se desean modificar o impactar (por ejemplo, función pulmonar). ${ }^{54,55}$ Dupilumab es el primer biotecnológico dirigido a la señalización de IL-4/IL-13 en asma y, con este mecanismo único, al bloquear las rutas de señalización de la inflamación tipo 2 y demostrar la reducción de biomarcadores de este tipo de inflamación, sugeriría que sus efectos sobre la inflamación o alcance terapéutico pudieran ser más amplios que los de los agentes de señalización anti-IL-5. Dupilumab mostró eficacia en varios subgrupos de pacientes con biomarcadores elevados de inflamación tipo 2, incluidos niveles elevados de EOS en sangre o de la FeNO, tendiendo a un resultado terapéutico más destacado en estas subpoblaciones, consistente con las indicaciones con las cuales se aprobó dupilumab y con las que se recomienda en las guías internacionales. ${ }^{16,53,54,55}$

Hasta la fecha, dupilumab solo ha sido comparado con otros agentes monoclonales indirectamente en metaanálisis de red, ${ }^{23,56,57}$ cuyos hallazgos requieren ser interpretados con precaución debido a la naturaleza de las comparaciones y a la probable heterogeneidad de las poblaciones o los estudios evaluados. Los resultados en este tipo de metaanálisis demostraron que dupilumab podría ser el un anticuerpo monoclonal más eficaz, principalmente en términos de la magnitud de su efecto sobre las puntuaciones de FEV1 y de los cuestionarios de control del asma y calidad de vida en pacientes con asma, así como en las exacerbaciones de asma. ${ }^{23,57}$ Probablemente la razón por la cual dupilumab destaca es porque se trata de un bloqueador de receptor dual para IL-4 e IL-13, en comparación con otros agentes biológicos que bloquean selectivamente vías únicas (por ejemplo, IL-5 o IL-13). ${ }^{56}$ Estos análisis tiene limitaciones al no incluir otros productos biológicos que se han probado en pacientes con asma, como pitakinra, tezepelumab y otros dirigidos a IL-25 e IL-33. ${ }^{58}$

Cabe mencionar que los pacientes que reciben dupilumab para el tratamiento de asma con inflamación tipo 2 /fenotipo eosinofílico también pueden experimentar mejoría en comorbilidades fisiopatológicamente inducidas por este tipo de inflamación. $\mathrm{La}$ experiencia clínica adicional probablemente ayudará a determinar el alcance de este beneficio potencial, ${ }^{23}$ aunque los estudios pivotales han demostrado este fenómeno al tratar con dupilumab a pacientes con dermatitis atópica y asma comórbida o rinosinusitis crónica; hasta el momento hay evidencia de que las tres afecciones han mejorado con el tratamiento biotecnológico. $9,17,59,60,61,62,63,64$

Dupilumab fue generalmente bien tolerado en asma y en los ensayos clínicos no aumentó el riesgo de conjuntivitis, evento adverso asociado a este agente en pacientes con dermatitis atópica. ${ }^{13,16,43}$ Aunque con el tratamiento se observaron elevaciones transitorias en los niveles circulantes de EOS, generalmente no tenían consecuencias clínicas ni efectos adversos y es probable que se debieran a la inhibición de la migración de EOS mediada por IL-4 e IL-13 a los tejidos, sin afectar la producción de EOS en la médula ósea médula.

En conclusión, el dupilumab es una opción terapéutica valiosa con una eficacia rápida, sostenida y un perfil de seguridad muy amplio en pacientes menores de 12 años que tienen asma moderada a grave con inflamación tipo 2 fenotipo eosinofílico a pesar del tratamiento convencional o que dependen de CEO para controlar la enfermedad. 


\section{Referencias}

1. Fahy JV. Type 2 inflammation in asthma-present in most, absent in many. Nat Rev Immunol. 2015;15[1]:5765. DOl: $10.1038 /$ nri3786

2. Busse WW. Biological treatments for severe asthma: A major advance in asthma care. Allergol Int. 2019;68(2):158-166. DOl: 10.1016/j.alit.2019.01.004

3. Bagnasco D, Ferrando M, Varricchi G, Passalacqua G, Canonica GW. A critical evaluation of anti-IL-13 and antiIL-4 strategies in severe asthma. Int Arch Allergy Immunol. 2016;170[2]:122-131. DOI: 10.1159/000447692

4. Kortekaas-Krohn I, Bal SM, Golebski K. The role of innate lymphoid cells in airway inflammation: evolving paradigms. Curr Opin Pulm Med. 2018;24(1):11-17. DOl: 10.1097/MCP.0000000000000435

5. Corren J. New targeted therapies for uncontrolled asthma. J Allergy Clin Immunol Pract. 2019;7[5]:13941403. DOI: 10.1016/j.jaip.2019.03.022

6. Diamont Z DS-E. Type 2 inflammation and the evolving profile of uncontrolled persistent asthma. Eur Med J. 2018;3[4]:24-33. Disponible en: https://emj.emg-health.com/wp-content/uploads/sites/2/2018/12/ Type-2-Inflammation-and-the-Evolving....pdf

7. Food and Drug Administration. Dupixent [dupilumab] injection. EE. UU.; 2019. Disponible en: https://www. accessdata.fda.gov/drugsatfda_docs/label/2017/761055lbl.pdf

8. Sanofi-Aventis. Dupilumab solution for injection: summary of product characteristics. 2019. [Consultado: 2020 Nov 28]. Disponible en: https://www.ema.europa.eu

9. Grey A, Katelaris CH. Dupilumab in the treatment of asthma. Immunotherapy. 2019;11(10):859-872. DOI: 10.2217/imt-2019-0008

10. Wenzel S, Ford L, Pearlman D, Spector S, Sher L, Wang L, et al. Dupilumab in persistent asthma with elevated eosinophil levels. N Engl J Med. 2013;368[26]:2455-2466. DOl: 10.1056/NEJMoa1304048

11. Wenzel S, Castro M, Corren J, Maspero J, Wang L, Zhang B, et al. Dupilumab efficacy and safety in adults with uncontrolled persistent asthma despite use of medium-to-high-dose inhaled corticosteroids plus a long-acting beta2 agonist: a randomised double-blind placebo-controlled pivotal phase $2 \mathrm{~b}$ dose-ranging trial. Lancet. 2016;388(10039):31-44. D0I: 10.1016/S0140-6736[16]30307-5

12. Busse WW, Maspero JF, Rabe KF, Papi A, Wenzel SE, Ford LB, et al. Liberty Asthma QUEST: phase 3 randomized, double-blind, placebo-controlled, parallel-group study to evaluate dupilumab efficacy/safety in patients with uncontrolled, moderate-to-severe asthma. Adv Ther. 2018;35(5):737-748. DOI: 10.1007/s12325-018-0702-4

13. Rabe KF, Nair P, Brusselle G, Maspero JF, Castro M, Sher L, et al. Efficacy and safety of dupilumab in glucocorticoid-dependent severe asthma. N Engl J Med. 2018;378[26]:2475-2485. DOl: 10.1056/ NEJMoa1804093

14. Corren J, Castro M, Ford LB, Bernstein A, Maroni J,Rowe P, et al. Dupilumab improves asthma outcomes irrespective of frequency of previous asthma exacerbation history. Ann Allergy Asthma Immunol. 2019;123(2):222-224 e221. DOI: 10.1016/j.anai.2019.04.028

15. Castro M, Corren J, Pavord ID, Maspero J, Wenzel S, Rabe KF, et al. Dupilumab efficacy and safety in moderateto-severe uncontrolled asthma. N Engl J Med. 2018;378[26]:2486-2496. DOl: 10.1056/NEJMoa1804092

16. Castro M, Rabe KF, Corren J, et al. Dupilumab improves lung function in patients with uncontrolled, moderate-to-severe asthma. ERJ Open Res. 2020;6(1):00204-02019. DOl: 10.1183/23120541.00204-2019

17. Maspero JF, Katelaris $\mathrm{CH}$, Busse WW, et al. Dupilumab efficacy in uncontrolled, moderate-to-severe asthma with self-reported chronic rhinosinusitis. J Allergy Clin Immunol Pract. 2020;8[2]:527-539.e529. D0I: 10.1016/j.jaip.2019.07.016

18. Bachert C, Hellings PW, Mullol J, Naclerio RM, Chao J, Amin N, et al. Dupilumab improves patient-reported outcomes in patients with chronic rhinosinusitis with nasal polyps and comorbid asthma. J Allergy Clin Immunol Pract. 2019;7[7]:2447-2449.e2. D0l: 10.1016/j.jaip.2019.03.023

19. Swanson BN TA, Hamilton JD, et al. Dupilumab suppresses fractional exhaled nitric oxide (FeNO) and biomarkers of type 2 inflammation in adult patients with persistent uncontrolled asthma despite use of medium-to-high dose inhaled corticosteroids plus long-acting beta-agonists [ICS/LABAs]. J Allergy Clin Immunol. 2016;137[2]:AB190. D0l:https://DOl.org/10.1016/j.jaci.2015.12.752

20. Pharmaceuticals and Medical Devices Agency [sitio web]. Japón: Report on the Deliberation Results; 2017. [Consultado: २०2० Nov 28]. Disponible en: https://www.pmda.go.jp/files/000235351.pdf 
21. Li Z, Radin A, Li M, et al. Pharmacokinetics, pharmacodynamics, safety, and tolerability of dupilumab in healthy adult subjects. Clin Pharmacol Drug Dev. 2020;9[6]. D0I: 10.1002/cpdd.798

22. Matera MG, Calzetta L, Rogliani P, Cazzola M. Monoclonal antibodies for severe asthma: Pharmacokinetic profiles. Respir Med. 2019;153:3-13. D0l: 10.1016/j.rmed.2019.05.005

23. Calzetta L, Matera MG, Rogliani P. Monoclonal antibodies in severe asthma: is it worth it? Expert Opin Drug Metab Toxicol. 2019;15[6]:517-520. DOl: 10.1080/17425255.2019.1621837

24. Matera MG, Rinaldi B, Calzetta L, Cazzola M. Pharmacogenetic and pharmacogenomic considerations of asthmatreatment.ExpertOpinDrugMetabToxicol.2017;13(11):1159-1167.DOI:10.1080/17425255.2017.1391215

25. Wenzel SE, Wang L, Pirozzi G. Dupilumab in persistent asthma. N Engl J Med. 2013;369(13):1276. DOI: 10.1056/ NEJMc1309809

26. Corren J, Castro M, Chanez P, Fabbri L, Amin N, Mastey V, et al. Dupilumab improves symptoms, quality of life, and productivity in uncontrolled persistent asthma. Ann Allergy Asthma Immunol. 2019;122[1]:41-49 e42. DOl: 10.1016/j.anai.2018.08.005

27. Katial RK, Bensch GW, Busse WW, Chipps BE, Denson JL, Gerber AN, et al. Changing paradigms in the treatment of severe asthma: the role of biologic therapies. J Allergy Clin Immunol Pract. 2017;5[2S]:S1-S14. DOI: 10.1016/j.jaip.2016.11.029

28. Papi A, Swanson B, Staudinger H, Rowe P, Maroni J, Hamilton J, et al. Dupilumab rapidly and significantly improves lung function and decreases inflammation by 2 weeks after treatment initiation in patients with uncontrolled persistent asthma. Am J Resp Crit Care Med. 2017;195:A6444.

29. Castro M, Busse WW, Zhang B, Maroni J, Rowe P, Amin N, Pirozzi G, et al. Dupilumab treatment produces rapid and sustained improvements in FEV1 in patients with uncontrolled, moderate-to-severe asthma from the LIBERTY ASTHMA QUEST study. Am J Resp Crit Care Med. 2018;197:A6489.

30. Corren J, Bousquet J, Busse WW, Maspero J, Hanania N, Ford LB, al. Dupilumab suppresses inflammatory biomarkers in asthma patients with or without allergic rhinitis: post hoc analysis of the LIBERTY ASTHMA QUEST Study. J Allergy Clin Immunol. 2019;143[2]:AB97. D0l: 10.1016/j.jaci.2018.12.297

31. Ramsahai JM, Hansbro PM, Wark PAB. Mechanisms and management of asthma exacerbations. Am J Respir Crit Care Med. 2019;199(4):423-432. DOI: 10.1164/rccm.201810-1931CI

32. Pavord I, Ford LB, Corren J, al. e. Dupilumab reduces exacerbations and improves lung function in uncontrolled, moderate-tosevere asthma patients regardless of prior exacerbation history in the phase 3 Liberty Asthma Quest Study. Thorax. 2018;73(Suppl4):A121-122. D0l: 10.1136/ thorax-2018-212555.202

33. Busse WW, Maspero JF, Lu Y, et al. Dupilumab improves clinical outcomes in patients with asthma and perennial allergic rhinitis. Ann Allergy Asthma Immunol. 2020;125[5]:565.576. D0I: 10.1016/j. anai.2020.05.026

34. Busse WW, Maspero JF, Hanania NA, FitzGerald JM, Ford LB, Rice M, et al. Dupilumab improves lung function and reduces severe exacerbation rate in patients with uncontrolled, moderate-to-severe asthma with or without comorbid allergic rhinitis: results from the phase 3 LIBERTY ASTHMA QUEST study. J Allergy Clin Immunol. 2019;143[2]:AB97. D0I: 10.1016/j.jaci.2018.12.296

35. Katelaris C, Rabe K, Corren J, Langton D, Bardin P, Park H, et al. Dupilumab improves asthma outcomes regardless of baseline lung function. Respirology. 2019;24:110.

36. Agache I, Rocha C, Beltran J, Song Y, Posso M, Akdis C, et al. Efficacy and safety of treatment with biologicals [benralizumab, dupilumab and omalizumab] for severe allergic asthma: a systematic review for the EAACI Guidelines - recommendations on the use of biologicals in severe asthma. Allergy. 2020;75(5):1043-1057. DOl: 10.1111/all.14235

37. Agache I, Beltran J, Akdis C, Akdis M, Casale T, Chivato T, et al. Efficacy and safety of treatment with biologicals [benralizumab, dupilumab, mepolizumab, omalizumab and reslizumab] for severe eosinophilic asthma. A systematic review for the EAACI Guidelines - recommendations on the use of biologicals in severe asthma. Allergy. 2020;75[5]:1023-1042. DOl: 10.1111/all.14221

38. Korn S, Corren J, Castro M, Maspero J, Chen Z, Niemann I, et al. Dupilumab improved asthma control in patients with uncontrolled, moderate-to-severe asthma, regardless of exacerbations in the previous year. Pneumologie. 2019;73. D0I: 10.1055/s-0039-1678039 
39. Castro M, Rabe KF, Brusselle G, Rice MS, Rowe P, Deniz Y, et al. Dupilumab effect on asthma control and health-related quality of life in patients with oral corticosteroid-dependent severe asthma with comorbid chronic rhinosinusitis with and without nasal polyps. Eur J Allergy Clin Immunol. 2019;74[106]:77.

40. Weinstein SF, Katial R, Jayawardena S, Pirozzi G, Eckert L, Jooish VN, et al. Efficacy and safety of dupilumab in perennial allergic rhinitis and comorbid asthma. J Allergy Clin Immunol. 2018;142(1):171-177.e171. DOl: 10.1016/j.jaci.2017.11.051

41. Maspero J, Busse WW, Katelaris CH, et al. Dupilumab improves health related quality of life in uncontrolled, moderate-to-severe asthma patients with comorbid allergic rhinitis from the phase 3 LIBERTY ASTHMA QUEST study. Eur J Allergy Clin Immunol. 2018;73:30-31.

42. Maspero JF, Rabe KF, Castro M, et al. Dupilumab improves health-related quality of life in patients with oral corticosteroid-dependent, severe asthma with comorbid chronic rhinosinusitis with and without nasal polyps. [Abstract]. W 2019;74[Suppl 106]:35-36.

43. Muneswarao J, Hassali MA, Ibrahim B, Saini B, Ali IAH, Verma AK. It is time to change the way we manage mild asthma: an update in GINA 2019. Respir Res. 2019;20[1]:183. DOl: 10.1186/s12931-019-1159-y

44. Akinlade B, Guttman-Yassky E, de Bruin-Weller M, Simpson EL, Blauvelt A, Cork MJ, et al. Conjunctivitis in dupilumab clinical trials. Br J Dermatol. 2019;181[3]:459-473. DOI: 10.1111/bjd.17869

45. Raherison C, Deschildre A, Garcia G, Girodet PO, Taillé C, Moilimard M, et al. Management of mild asthma in 2019-2020: What about new international therapeutic proposals [GINA 2019]? Rev Mal Respir. 2020;37[5]:427-432. DOl: 10.1016/j.rmr.2020.03.005

46. Hogan AD, Bernstein JA. GINA updated 2019: landmark changes recommended for asthma management. Ann Allergy Asthma Immunol. 2020;124[4]:311-313. D0I: 10.1016/j.anai.2019.11.005

47. Settipane RA, Kreindler JL, Chung Y, Tkacz J. Evaluating direct costs and productivity losses of patients with asthma receiving GINA 4/5 therapy in the United States. Ann Allergy Asthma Immunol. 2019;123[6]:564572 e563. DOl: 10.1016/j.anai.2019.08.462

48. McDonald VM, Maltby S, Gibson PG. Severe asthma: can we fix it? Prologue to seeking innovative solutions for severe asthma. Respirology. 2017;22(1):19-20. D0l: 10.1111/resp.12956

49. McDonald VM, Yorke J. Adherence in severe asthma: time to get it right. Eur Respir J. 2017;50[6]:1702191. DOI: 10.1183/13993003.02191-2017

50. Boulet LP, Reddel HK, Bateman E, Pedersen S, FitzGerald JM, O'Byrne PM. The Global Initiative for Asthma [GINA): 25 years later. Eur Respir J. 2019;54[2]:1900598. DOl: 10.1183/13993003.00598-2019

51. Rogliani P, Calzetta L, Matera MG, Laitano R, Ritondo BL, Cazzola M, et al. Severe asthma and biological therapy: when, which, and for whom. Pulm Ther. 2020;6(1):47-66. D0l: 10.1007/s41030-019-00109-1

52. Asthma: updated diagnosis and management recommendations from GINA. Am Fam Physician. 2020;101[12):762-763.

53. Difficult-to-treat \& severe asthma in adolescent and adult patients. Diagnosis and management. EE. UU.: Global Initiative for Asthma; 2019. Disponible en: https://ginasthma.org/wp-content/uploads/2019/04/ GINA-Severe-asthma-Pocket-Guide-v2.0-wms-1.pdf

54. Agache I, Akdis C, Akdis M, Canonica GW, Casale T, Chivato T, et al. EAACl biologicals guidelines recommendations for severe asthma. Allergy. 2020. DOI: 10.1111/all.14425

55. Agache I, Song Y, Rocha C, Beltran J, Posso M, Steiner C, et al. Efficacy and safety of treatment with dupilumab for severe asthma: a systematic review of the EAACI guidelines-recommendations on the use of biologicals in severe asthma. Allergy. 2020;75[5]:1058-1068. DOI: 10.1111/all.14268

56. Iftikhar IH, Schimmel M, Bender W, Swenson C, Amrol D. Comparative efficacy of anti IL-4, IL-5 and IL-13 drugs for treatment of eosinophilic asthma: a network meta-analysis. Lung. 2018;196[5]:517-530. D0l: 10.1007/s00408-018-0151-5

57. Edris A, de Feyter S, Maes T, Joos G, Lahousse L. Monoclonal antibodies in type 2 asthma: a systematic review and network meta-analysis. Respir Res. 2019;20[1]:179. DOl: 10.1186/s12931-019-1138-3

58. Koczulla AR, Vogelmeier CF, Garn H, Renz H. New concepts in asthma: clinical phenotypes and pathophysiological mechanisms. Drug Discov Today. 2017;22[2]:388-396. DOI: 10.1016/j.drudis.2016.11.008

59. Jonstam K, Swanson BN, Mannent LP, Tian N, Wang Y,Zhang D, etal. Dupilumab reduces local type 2 pro-inflammatory biomarkers in chronic rhinosinusitis with nasal polyposis. Allergy. 2019;74[4]:743-752. DOl: 10.1111/all.13685 
60. Xu X, Zheng Y, Zhang X, He Y, Li C. Efficacy and safety of dupilumab for the treatment of moderate-to-severe atopic dermatitis in adults. Oncotarget. 2017;8[65]:108480-108491. DOl: 10.18632/oncotarget.22499

61. Laidlaw TM, Mullol J, Fan C, Zhang D, Amin N, Khan A, et al. Dupilumab improves nasal polyp burden and asthma control in patients with CRSwNP and AERD. J Allergy Clin Immunol Pract. 2019;7[7]:2462-2465.e1. DOl: 10.1016/j.jaip.2019.03.044

62. Bachert C, Han JK, Desrosiers M, Hellings PW, Amin N, Lee SE, et al. Efficacy and safety of dupilumab in patients with severe chronic rhinosinusitis with nasal polyps (LIBERTY NP SINUS-24 and LIBERTY NP SINUS-52): results from two multicentre, randomised, double-blind, placebo-controlled, parallel-group phase 3 trials. Lancet. 2019;394(10209):1638-1650. DOI: 10.1016/S0140-6736[19]31881-1

63. Thaci D, Simpson EL, Deleuran M, Kataoka Y, Chen Z, et al. Efficacy and safety of dupilumab monotherapy in adults with moderate-to-severe atopic dermatitis: a pooled analysis of two phase 3 randomized trials [LIBERTY AD SOLO 1 and LIBERTY AD SOLO 2). J Dermatol Sci. 2019;94[2]:266-275. DOI: 10.1016/j. jdermsci.2019.02.002

64. de Bruin-Weller M, Thaci D, Smith CH, et al. Dupilumab with concomitant topical corticosteroid treatment in adults with atopic dermatitis with an inadequate response or intolerance to ciclosporin $A$ or when this treatment is medically inadvisable: a placebo-controlled, randomized phase III clinical trial (LIBERTY AD CAFE]. Br J Dermatol. 2018;178[5]:1083-1101. DOl: 10.1111/bjd.16156

65. Gandhi NA, Bennett BL, Graham NMH, Pirozzi G, Stahl N, Yancopoulos GD, et al. Nat Rev Drug Discov. 2016;15[1]:35-50. DOl: 10.1038/nrd4624 